NBER WORKING PAPER SERIES

\title{
CROSS-COUNTRY COMPARISON OF OLD AGE FINANCIAL READINESS IN ASIAN COUNTRIES VS. THE UNITED STATES: THE CASE OF JAPAN AND THE REPUBLIC OF KOREA
}

\author{
Isaac Ehrlich \\ Yong Yin \\ Working Paper 29649 \\ http://www.nber.org/papers/w29649 \\ NATIONAL BUREAU OF ECONOMIC RESEARCH \\ 1050 Massachusetts Avenue \\ Cambridge, MA 02138 \\ January 2022
}

Isaac Ehrlich (corresponding author): SUNY and UB Distinguished Professor and Melvin H. Baker Professor of American Enterprise, School of Management, State University of New York at Buffalo. Email: mgtehrl@buffalo.edu; Yong Yin: Research Assistant Professor, Department of Economics, State University of New York at Buffalo. Email: yyin@buffalo.edu. This analysis uses data or information from the Harmonized JSTAR dataset and Codebook, Version B as of August 2014, and from the Harmonized KLoSA dataset and Codebook, Version C as of June 2019, both developed by the Gateway to Global Aging Data. The development of the Harmonized JSTAR and KLoSA was funded by the National Institute on Ageing (R01 AG030153, RC2 AG036619, R03 AG043052). For more information, please refer to www.g2aging.org. We acknowledge financial assistance through TA-9921 REG: Global Research Alliances (Phase 3). We also thank Yasuyuki Sawada and Jesus Felipe for helpful comments on an earlier draft. The views expressed herein are those of the authors and do not necessarily reflect the views of the National Bureau of Economic Research.

At least one co-author has disclosed additional relationships of potential relevance for this research. Further information is available online at http://www.nber.org/papers/w29649.ack

NBER working papers are circulated for discussion and comment purposes. They have not been peer-reviewed or been subject to the review by the NBER Board of Directors that accompanies official NBER publications.

(C) 2022 by Isaac Ehrlich and Yong Yin. All rights reserved. Short sections of text, not to exceed two paragraphs, may be quoted without explicit permission provided that full credit, including ( $)$ notice, is given to the source. 
A Cross-Country Comparison of Old Age Financial Readiness in Asian Countries vs. the United States: The Case of Japan and the Republic of Korea

Isaac Ehrlich and Yong Yin

NBER Working Paper No. 29649

January 2022

JEL No. G11,G12,G32,G51

\begin{abstract}
We pursue a cross-country comparison of relative financial readiness of older households in Japan and the Republic of Korea relative to the US. Our comparative analysis, using macro-level and harmonized longitudinal household financial data, covers the principal financial channels of old age support: public and private pension plans, family support, and self-management of private financial portfolios. We find that while all three countries have similar public pension systems, older Americans benefit from more developed and better-funded public and private pension systems, as well as individual management of risky financial portfolios. We find that educational and health attainments of household heads and household wealth lead to a greater tendency to hold and manage risky assets. Our decomposition analysis also shows that the gap in stock ownership in Asian countries relative to the US is attributable to lower development levels of financial and pension markets. However, these gaps are shrinking more recently.
\end{abstract}

\author{
Isaac Ehrlich \\ Department of Finance and \\ Department of Economics \\ and Center for Human Capital \\ State University of New York at Buffalo \\ Buffalo, NY 14260-1520 \\ and NBER \\ mgtehrl@buffalo.edu \\ Yong Yin \\ 415 Fronczak Hall \\ State University of New York at Buffalo \\ and Center for Human Capital \\ Box 601520 \\ Buffalo, NY 14260 \\ yyin@buffalo.edu
}




\section{Introduction}

The financial well-being and inclusion of older age groups and retirees has long been an issue of academic interest as well as public concern in the modern welfare states. The concern is based on the idea that large segments of the population may not be able to adequately secure their financial well-being after retirement through their accumulated savings, and thus need to be supplemented by private (typically employer- or employee-based plans) and public pension systems. The traditional private old-age support system has consisted largely of informal "family insurance" arrangements whereby adult children or extended family members would provide care and material support for their parents and close relatives. With the development of modern enterprises and financial markets, old-age support started coming from employer severance payments to retirees, and employer-based or private pension funds. To better deal with old-age financial needs, however, welfare states, starting with Germany in 1889 and the United States (US) in 1935, have established old-age social insurance programs to supplement the private old-age support mechanisms. According to the Organization for Economic Co-operation and Development (OECD 2019), the combined old-age financial support systems in the OECD countries - private and public - provide a gross pension replacement rate of $49 \%$ for men and $48,2 \%$ for women earning average incomes. Asian countries have also developed such systems, but largely only after the World War II.

The retirement-income support systems in both Western and Asian countries have been facing increasing financial vulnerability, however, due to the ongoing demographic transition process and some slowdown in global economic growth, especially in developed countries. Total fertility rates in the more developed region (MDR) ${ }^{1}$ - a term used by the United Nations which includes all European and North American countries plus Australia, New Zealand, and Japan-have fallen significantly from 2.82 during the 5-year period ending in 1955 to 1.57 in the 5 -year period ending in 2000 . They have risen only modestly since then and are predicted to reach 1.71 in 2040 (Figure 1). Over the same period, life expectancy at age 65 in the MDR increased from an average of 13.46 years in 1950-1955 to 16.12 years in 1985-1990 before accelerating to 19.57 years in 2015-2020 (Figure 2). These aging trends have contributed, in

\footnotetext{
${ }^{1}$ The more developed region is a term used by the United Nations. The region includes all European and Northern American countries, plus Australia, New Zealand, and Japan.
} 
turn, to a steady increase in the old-age to working-age dependency ratio, which is measured as the ratio of the number of people age 65 and over for every 100 people age 20 to 64 in 1950 . This number has risen from 13.6 in 1950 to 21 in 1990, and it was predicted to rise to 32.7 in 2020 and to an alarming 46.3 by 2040 (Figure 3 ).

[Insert Figure 1 here]

[Insert Figure 2 here]

[Insert Figure 3 here]

In the US, the inversely related potential old-age support ratio fell from 6 in 1960 to an expected 3.6 in 2020, while in Japan it shrunk from 8.7 to 2.2 in 2015 . $^{2}$ This has put tremendous financial stress on both public and private defined-benefits pension systems around the world. The challenges have led to reforms in retirement income systems in recent years, including increases in the eligible age for full social security, more use of means tests, and a shift from defined-benefit to defined-contribution pension schemes in both the public and private sectors.

One of the potential remedies that could mitigate the increasing prospect of financial insolvency of private and public pension programs is for households to improve the management of their individually held retirement assets. Households can meet this challenge by raising their participation in risky financial markets and increasing their demand for shares of stocks and corporates bonds they hold in their individual portfolios. However, the current participation rate of households in risky financial markets remains low even in the most developed economies. Using the US Health and Retirement Study (HRS), Ehrlich and Yin (2020) report that just 24\% to 34\% of American households held stocks. ${ }^{3}$ Venti and Wise (2001) used the first wave of HRS data to illustrate that a considerable amount of the dispersion in wealth among US households is due to investments in less risky assets such as bonds or bank saving accounts as opposed to more risky assets such as stocks and corporate bonds.

\footnotetext{
${ }^{2}$ See https://www.prb.org/the-u-s-population-is-growing-older-and-the-gender-gap-in-life-expectancy-is-narrowing/ and https://knoema.com/atlas/Japan/topics/Demographics/Dependency-Ratios/Potential-support-ratio-20-64-per-65.

${ }^{3}$ Ehrlich, Hamlen, and Yin 2008 report similar percentages using the Survey of Consumer Finance. It is interesting to note that Ehrlich and Shin (2020) report similar percentages for European households (24\%) using the Survey of Health, Ageing and Retirement in Europe (SHARE).
} 
The recent changing structure of employer-based pension plans in many countries from defined-benefits to defined-contribution schemes have two opposite impacts on employees. On the one hand, this change shifts the onus of financial management of assets - the selection, allocation, and management of the household financial portfolios - from employers to employees, thrusting unprepared employees into a bigger, challenging role. On the other hand, such experiences might exert offsetting effects going forward by preparing the same employees to better manage their retirement portfolio during the retirement.

The need for better asset management during retirement has also intensified because retirees are now facing longer life spans due to continued increases in life expectancy, especially at older age brackets. This would increase the risk that aging households would become totally dependent on government old-age pension plans when they deplete their portfolio of assets. This factor impacts especially those households that reach retirement age with a relatively low level of accumulated wealth.

To understand the mechanism of an individual's asset management choices and potential portfolio outcomes, Ehrlich, Hamlen, and Yin (2008) developed a theoretical framework for asset management. This framework was extended in a later study (Ehrlich, Shin, and Yin 2011; Ehrlich and Shin 2010), focusing on the willingness to hold both domestic and foreign risky assets and the role of education and health in asset accumulation by older age groups in the US using HRS data (Ehrlich and Yin 2021). In this paper, we greatly extend the same framework to study simultaneously the factors affecting the demand for holding risky assets in two Asian countriesJapan and the Republic of Korea (ROK) - and the US. One reason for selecting these countries is that they represent three OECD countries in different stages of development, with the US having the most developed and experienced financial industry, Japan ranking second behind the US, and the ROK having the least developed financial industry. Another important reason is that these three countries have a relatively comparable micro-level longitudinal survey-type data (HRS, JSTAR, and KLoSA), although the Japanese survey differs somewhat by specific characteristics, which we explore in later sections. The macro-level analysis leads to a better understanding of the role of the individual determinants of demand for risky asset holding relative to that of the market-level determinants. More specifically, our analysis has five major objectives: 
(i) analyzing and comparing the macro-level accumulated components of wealth by type of asset across the three countries along with comparing the overall characteristics of investors in the three countries:

(ii) reviewing the role of old-age pension systems - both private and public - in supporting the financial well-being of retirees;

(iii) estimating the role of individual investors' characteristics in explaining household willingness to hold risky financial assets to achieve better outcomes in accumulating total and financial assets near and during retirement;

(iv) decomposing the role of individual characteristics, as predicted by our theoretical model, relative to the role of financial market development in explaining gaps in households' willingness to hold risky assets across different countries, by using an econometric decomposition analysis; and

(v) deriving some general policy implications based on our findings from the preceding objectives.

The remaining sections of this paper are organized as follows. In Section II, we briefly describe the retirement income systems and demographic characteristics of the three countries we analyze. In Section III, we describe the data surveys used in our analysis. Section IV contains the basic descriptions of household characteristics, retirement decisions, income sources, and wealth distributions in these three countries. In Section V, we develop our theoretical model of asset management and apply it empirically via a regression analysis using micro data and through a decomposition analysis. We conclude with the main policy implications of our findings.

\section{Comparing the Retirement-Income Systems in Japan, the Republic of Korea, and the US}

We compare the retirement-income systems in Japan, the ROK, and the US in terms of their completeness - the combination of both public and private components - supporting demographic factors, and funding strength.

\section{A. Japan}


Japan has a two-tier public pension plan (Rajnes 2007 and SSA 2008): the employees' pension insurance (EPI), which was established by law in 1941 and was later updated in 1954; and the national pension (NP) law, which was introduced in 1959 and amended in 1985. The current system can be described as a social insurance system, which involves a flat-rate benefit for all residents under the national pension program (first tier) and earnings-related benefits under the employees' pension insurance program or other employment-related program. The full pensionable age for NP was 60 years old in 2001 but started to increase by one year every three years to 65 by 2013. The early pensionable age is currently 60 . For EPI, the eligible age was also 60 in 2001. But starting in 2013 it increased by one year every three years for men until it reaches 65 in 2025. For women, the eligible age also started rising in 2018 by one year every three years until it reaches 65 in 2030. The full benefit requires a minimum of 40 years of contributions, and reduced benefit requires at least 25 years of contributions. Both NP and EPI also provide disability insurance depending on meeting disability criteria as well as a contribution requirement (SSA 2008).

The private sector in Japan also offers voluntary employer-sponsored retirement plans, with retirement typically mandated at age 60 . There had been two defined-benefit (DB) plans offered, both receiving preferential tax treatment (Raines 2007). Two laws were passed in 2001 with the aim of reforming these plans. The DB plans went through a major overhaul to address underfunding problems and allow for convertibility to a DC plan. In addition, influenced by the expanding US economy and stock market boom of the 1990s that was enhanced by the growth of DC plans, primarily 401(k)'s in the US, a separate legislation established both corporate and individual defined-contribution (DC) plans with the aim of stimulating the flow of individual retirement account assets into Japanese financial markets.

In 2019, the gross pension replacement rates for Japanese retirees with mean earnings were projected by OECD pension models to be $32.5 \%$ for public plans and $23.8 \%$ for private plans (OECD 2019). The total gross replacement rate, which includes total mandatory and voluntary plans, is thus $55.8 \%$. By comparison, the OECD average replacement rate for public plans and private, voluntary plans are $39.6 \%$, and $55.2 \%$, respectively. Compared with other OECD countries, the Japanese public system is less generous, but it offers better overall income security by combining private and public sources. 


\section{B. Republic of Korea}

The ROK has a national pension (NP) system for all citizens except government employees, private teachers, military personnel, and employees of the special post office, who are covered in a separate, special occupational pension program. Both plans are mandatory. These were established by law in 1986 and later updated in 2007. In 2008, the eligibility age for full pension benefits was set at 60 years old, requiring at least 20 years of employment coverage. This age is set to gradually increase, however, to 65 by 2033. The early eligibility age was 55 in 2008, but this is also set to gradually rise to 60 by 2033 (SSA 2008). NP provides a basic old-age pension for people over 65 with an income below a maximum set by presidential order, and this benefit is not subject to a minimum of 20 years of coverage. NP provides disability pension as well, depending on the degree of disability assessed by the National Pension Corporation.

The private sector in the ROK used to have a mandatory severance payment system (it started out as voluntary in 1953 and became mandatory in 1961) for businesses with more than five employees, which provided a defined benefit in the form of a lump-sum payment to employees. It was funded entirely by employers. This plan was replaced by the Korean retirement benefit system (RBS) in 2005. The RBS provides a choice between retirement pension plans (RPP) and retirement pay schemes (RPS), which corporations can form. There are two types of RPPDC and DB plans - while RPS is a DB plan by design. There are also voluntary personal pension plans in the form of individual retirements accounts (IRAs) that have been available in the ROK since 1994 (OECD 2009).

According to OECD pension models, the gross pension replacement rates in 2019 for retirees with mean earnings in the ROK is $37.7 \%$ for mandatory public plans. There is no estimated figure available, however, for mandatory and voluntary private plans. Thus, the ROK offers a slightly less generous public pension system compared to its OECD peers, but the overall gross pension replacement rate is well below the OECD average of $55.2 \%{ }^{4}$

\section{The United States}

\footnotetext{
${ }^{4}$ As pointed out by one of our referees, the real-world situation in the ROK is even worse. The OECD pension models make an unrealistic assumption concerning the number of years in which pension contributions have been made in that country. The actual number of contribution years is much lower. This is one of the factors contributing to the highest poverty rate among the elderly in the OECD.
} 
In the US, the basic public system is a pay-as-you-go social security system. The eligibility age for full benefits is 66 years old with at least 40 quarters of coverage, and the eligible age will be lifted to 67 by 2027 (SSA 2018). Early pensionable age is 62 with the same limitation on coverage. The US system offers a generous disability and supplemental income security for people with disabilities and acute needs.

The private sector in the US offers various types of voluntary retirement plans. Individuals can voluntarily contribute to additional retirement plans typically known as IRAs. In the US employment-based system, pension plans were originally dominated by DB plans. Starting around 1980, a quiet revolution took place: DC plans quickly rose to dominance over DB plans. By 2011, 93\% of covered private-sector workers participated in a DC plan, while only $31 \%$ participated in a DB plan (Ehrlich and Kim 2005). The sum exceeds 100\% because the same individual can simultaneously participate in multiple retirement plans.

The OECD pension models estimate that in 2019 the gross pension replacement rates for US retirees with mean earnings is $39.4 \%$ for mandatory public plans, which is virtually the same as the OECD average of $39.6 \%$. However, the gross replacement rate in the US, counting both mandatory and voluntary plans is $70.3 \%$, well above the OECD average of $55.2 \%$.

\section{Comparing the Demographic Changes Affecting the Retirement Systems in the Three Countries}

Figure 1 plots historical and projected total fertility rates for the three countries under consideration along with the average for the MDR as a benchmark. As the chart indicates, total fertility rate started to decline significantly in late 1970s for the US, but it recovered after the 1990s until the turn of the last century. It is currently projected to fall below the replacement rate going forward, but to remain above the average of the MDR. In Japan, the decline in total fertility rate accelerated in the 1970s, continuing into the 1990s. It is projected to be stable and to even recover somewhat in the near future, though it would remain significantly below the average in the MDR. The ROK is undergoing a more dramatic demographic transition. Its total fertility rate fell from 6.33 in 1960 to 2.92 in 1980 (around the time its economy started to take off) and fell even further 
to 1.5 in 2000, a level below the MDR average. ${ }^{5}$ The decline is projected to continue and then stabilize over the next two decades, but will remain well below that of MDR countries. It is noteworthy that the decline in total fertility rates in the ROK has been more rapid than that in Japan, and that the ROK's total fertility rate would remain significantly lower than that of Japan in the near future.

Figure 4 plots life expectancies at birth for these three countries, along with the average for MDR. While all countries have experienced steady increases in life expectancy over the last five decades, the rise in the ROK has been more dramatic. It rose quickly from 52.76 years in 1960 to 70.34 in 1990, and caught up with the US in 2005, reaching 77.17. It then surpassed both the US and the average of the MDR in 2010 and has narrowed the gap with Japan in recent years.

\section{[Insert Figure 4 here]}

Life expectancy trends at age 65 for these countries are plotted in Figure 3. If age 65 is taken to be the unofficial retirement age, the data suggest that in the 1960s people expected to live another 14 years during retirement. But by 2010 this number increased to 19 years. For Japan, which exhibits the highest life expectancy at 65 , longevity in retirement is currently expected to be 22.44 years (in 2020) and it is projected to reach 24.16 years in 2040. Japanese life expectancy at 65 caught up with that of the US around 1985, much sooner than the ROK, which achieved this feat around 2010.

The demographic transition in the three countries we survey — declining fertility along with rising life expectancy - has generated sharp increases in the shares of old-age population to total population in these countries. Figure 3 plots the old-age to working-age dependency ratio, defined as number of individuals age 65 and over for every 100 people age 20 to 64, for these countries. While the US and the ROK dependency ratios in 2020 of 28.4 and 23.6, respectively, are slightly below the average of 32.7 for the MDR, Japan's ratio of 52 is well above the average. The ratio is projected to go up to 46.3 for the average MDR in 2040. While the US would still see a figure below this average in 2040 (39.0), both Japan and the ROK (70.7 and 61.6, respectively) would be well above this average. Thus, based on these ratios, both the Japanese and Korean retirement-

\footnotetext{
${ }^{5}$ Note that in the recent decade there were years in which the fertility rate fell below one. However, the data exhibited in Figure 1 represent five-year averages, which do not fall below one.
} 
income systems will face a lot more headwinds than other more developed countries, including the US. This is especially true for the ROK as it started its mandatory retirement system much later than other countries, and the rate of increase in this ratio is almost exponential.

As for the extent to which the public pension system is funded, the US is in a much better place compared to its peers. According to OECD (2020a), in 2019, total assets in pension funds in the US equaled $87.5 \%$ of GDP, while this figure was only $28.4 \%$ for Japan and $11.6 \%$ for the ROK. By comparison, the OECD average was $60.1 \%$.

\section{E. Implications for the Relative Financial Strengths of the Retirement Systems in the Three Countries}

Based on the preceding comparisons of the structure and demographic trends affecting the private and public retirement systems across the three countries, it seems apparent that among the three countries, the US has the relatively most complete and funded public and private retirement system, including the traditional "family-support" system, due to its relatively higher fertility rate and retirement-income support ratio. Its demographic pattern going forward is also more favorable compared to the other two countries. In contrast, the ROK due to its late start and rapid decline in total fertility rate may face more serious challenges in the near term.

Table 1 reports the net pension average replacement rates of earnings for workers earning multiples of the mean earnings in the three countries, as estimated by the OECD pension models (OECD 2019), along with the OECD average replacement rates serving as reference points. As the table shows, the US provides better replacement rates of individual earnings relative to both the ROK and Japan, although all three countries fall below the OECD average rates. Japan, due to its relatively low reliance on the private sector, provides far less overall coverage relative to both the US and the ROK. By contrast, the ROK offers comparable replacement rates to those in the US only for workers earning $50 \%$ of mean earnings, while falling slightly short of Japan in terms of the replacement rate it offers for high earners - retirees who earn $150 \%$ of average earnings. This might be a reflection of the ROK's late start in pension reforms in the private sector.

[Insert Table 1 here]

It is interesting to note that, even though both Japan and the ROK have higher life expectancies at birth than the US ( 84.1 years for Japan and 82.63 years for the ROK compared to 
78.54 years for the US in 2017), both have set a pensionable age two years younger than that of the US. The pension eligible age is currently 65 years old in Japan - the same as the planned pension eligible age in the ROK, compared to 67 in the US. The lower eligibility ages in Japan and the ROK may accentuate the need for future potential reforms in the Japanese and Korean systems. In contrast, the OECD (2019) reported that in 2018, the ROK had the highest average effective age of labor market exit (72.3 for both men and women), Japan had the second highest averages (70.8 for men and 69.1 for women), the US had the third highest (67.9 for men and 66.5 for women), while the OECD countries had the lowest averages (65.4 for men and 63.7 for women). These differences translate into a remaining life expectancy in retirement of 12.9 years for men and 16.3 years for women in the ROK, 15.5 for men and 21.0 for women in Japan, and 16.4 for men and 19.8 for women in the US. In this regard, all three countries rank below the OECD average, where the average remaining life expectancy in retirement is 17.8 years for men and 22.5 years for women. These contrasting statistics suggest that both Japan and the ROK can mitigate their disadvantages in demographics and workers' dependencies on pension replacement rates because workers in these Asian countries tend to work longer than those in the US, and much longer than workers in most OECD countries.

\section{Data Description and Variable Construction}

\section{A. Comparative Samples and Waves}

Our study relies on three longitudinal studies sharing a common questionnaire design: the Health and Retirement Study (HRS) in the US, the Japanese Study of Aging and Retirement (JSTAR) in Japan, and the Korean Longitudinal Study of Aging (KLoSA) in the ROK.

The HRS is the seminal longitudinal household survey dataset that has been used to study retirement and health issues for the elderly in the US (Juster and Suzman 1995). The original survey was conducted in 1992, covering household heads who were age 50 to 60 at the time. The survey followed up with the original households every two years since then. A separate survey of the American oldest old population (AHEAD) was later merged with the original HRS. To maintain a continuing dynamic survey of the elderly population, a new cohort of households age 
50 and 55 has been added to the longitudinal survey every six years. Such refresher samples were added in 1998, 2004, 2010, and 2016.

The 2015 RAND HRS file version O, which we use in this study, is the result of several data developments aiming to provide a user-friendly version of HRS. ${ }^{6}$ It includes final data files from 12 waves (1992 to 2010). This longitudinal data contains only a subset of variables from the original HRS, but the survey reports cleaned and processed variables with consistent and intuitive naming conventions and model-based imputations. Most importantly it includes a large number of individual variables, including demographics, job status and history, health, as well as imputed income and assets. The success of HRS has inspired the development of similar surveys we use in our three-country study, as detailed below. Notable surveys also include the English Longitudinal Study of Ageing (ELSA) and the Survey of Health, Ageing, and Retirement in Europe (SHARE). All these studies share virtually identical questionnaires. This makes our cross-country comparison possible.

JSTAR is a panel survey of elderly people age 50 or older conducted by the Research Institute of Economy, Trade, and Industry (RIETI), Hitotsubashi University, and the University of Tokyo (Ichimura et al. 2009). The survey is designed to ensure, to the maximum extent possible, comparability with HRS, ELSA, and SHARE. To facilitate cross-country comparisons, RIETI also created the Harmonized JSTAR data to be compatible with the procedures and imputation methods employed in generating the RAND HRS. The JSTAR version we use is Version B.

JSTAR surveyed people between the ages of 50 and 75 along with their partners. The first wave was conducted in 2007 with five municipalities. The survey followed up with these households in wave 2 in 2009. Two more municipalities were added to the study in wave 2. All households were included in the follow-up wave 3 survey in 2011, along with three new municipalities added to the survey. The unit of analysis in JSTAR is the household, with survey weights at the household level provided for analysis. This differs from HRS where both personallevel and household-level survey weights are provided.

KLoSA is a panel survey in the ROK conducted initially by the Korean Institute of Labor. KLoSA started the first wave in 2006 for households with at least one person 45 years of age and

${ }^{6}$ For more details, see http://hrsonline.isr.umich.edu/modules/meta/rand/randhrso/randhrs_O.pdf. 
older, and the respondents were then surveyed every two years. Starting in wave 3, the data were collected by the Korea Employment Information Service (KEIS). There were no refresher samples in waves 2 through $4 .^{7}$ This difference may cause a downward bias when we aggregate individual data to form the household-level data. The data we use are the Harmonized KLoSA version C. We have obtained the original wave data from KEIS and then used a Stata program provided by a team at the Global Aging Project to generate the Harmonized version C data.

For comparison purposes, we used only waves 8, 9, and 10 from the RAND HRS, and waves 1, 2, and 3 from the Harmonized JSTAR and KLoSA. We note that KLoSA data were collected in the same year as the corresponding HRS, while JSTAR data were collected a year later (see Table 2 for details, which also includes the total number of units with non-zero survey weights in each wave). In this context we note that HRS added a fresh cohort in 2010, leading to a larger number of units compared with the previous two waves. For KLoSA, the number of units kept falling due to attrition, and this is also true for wave 9 of HRS compared with wave 8. In contrast, JSTAR added more municipalities in both the second and third waves, so the number of units in JSTAR have risen throughout the three waves. To achieve greater consistency among all three datasets, we also conduct the analysis at the household level. To capture individual characteristics such as age and education, however, we also use information on household heads.

[Insert Table 2 here]

We need to point out briefly some differences we observe in these three micro datasets when using the 2006-2007 wave. First, the household heads in HRS and JSTAR have similar average ages, with HRS exhibiting a slightly higher average. This is due to the introduction of a new cohort of individuals age 50 and 59 into the survey in 2004, which was the first wave of JSTAR. KLoSA reports a much lower average age because in the first wave of that survey, the age eligibility for KLoSA was 45, which was 10 years younger than the early pensionable age of 55 at the time. Throughout all waves, KLoSA contains much younger households, but the gap with HRS fell modestly in 2010 when a new cohort was added to HRS. Average age stayed almost the same between waves 1 and 2 for JSTAR even though there were more municipalities introduced in the

\footnotetext{
${ }^{7}$ One notable difference about KLoSA is that it does not interview spouses or partners younger than 45 , a deviation from the treatment in HRS and JSTAR.
} 
second wave. However, the average age in the JSTAR sample became older in wave 3, where more municipalities were included.

We should also note that even though we use the harmonized version of three micro datasets these data have their own limitations. For example, JSTAR does not use a national probabilistic sample. Furthermore, the micro datasets are often inconsistent with reported administrative data. Consequently, the data comparisons we report below should be viewed with caution, subject to this caveat.

\section{B. Comparative Key Variables}

To construct comparable variables in nominal local currencies, such as income and wealth, we first convert them into nominal US dollars using purchasing-power-parity (PPP) exchange rates (OECD 2020b), and then convert them into 2010 US constant dollars by using annual US consumer price indexes (CPI) available from the Bureau of Labor Statistics (BLS).

Table 3 reports our sample descriptive statistics for the demographic variables we use in our analysis, along with some key income and wealth variables. A quick glance would reveal that the three datasets remained quite stable across different waves.

[Insert Table 3 here]

Household size. The two Asian countries share a similar family size - around three-despite falling fertility rates, especially in Japan. However, the US has a family just size slightly above two. This is simply due to cultural differences, since children are more likely live with their parents in Asian countries. In all three countries, the household head is slightly more likely to be male, with the exception of the ROK in KLoSA's waves 2 and 3 where only $61 \%$ and $69 \%$ of household's heads are male. We use "coupled" as a dummy variable indicating whether a couple lives in the household. Those living separately, divorced, or widowed are not considered coupled. In the US sample, the coupled rate is slightly above $50 \%$ and is stable across waves. In the Korean sample, the coupled rate is surprisingly below 50\%. JSTAR reports a somewhat unstable pattern: this rate is $82.4 \%$ in wave 1 and $74.4 \%$ in wave 3 , but only $56.8 \%$ in wave 2 . 
Educational attainments. Only HRS reports continuous years of education. Both JSTAR and KLoSA report only educational attainments. For compatibility reasons, we use the following unified version of educational attainments: ${ }^{8}$

Educational attainment is classified as 1 for respondents with an educational attainment less than a high school degree; 2 for high school graduates; 3 for those with some college; and 4 for those with a college degree or higher. Among the three countries, the US has the highest average educational attainment in all waves, with the average being above a high school degree. Japan's average educational attainment is around a high school degree, while the ROK's average is just below a high school degree.

Retirement status. The data concerning individual retirement status are considerably different in the three countries. In Japan only $13.3 \%$ to $15.5 \%$ of the population report being fully retired. In the ROK the reported percentages are slightly higher at $15.4 \%$ to $20 \%$. But the in the US, the reported percentages are much higher - they range from $33.2 \%$ to $39.3 \%$.

Wage earners. The percentage of household heads who report working to earn a wage is very similar among the three countries, ranging from $42.9 \%$ to $49.4 \%$ across different waves.

Public pension receivers. The percentage of households receiving public pension is highest for Japan, ranging from $69.3 \%$ in 2009 to $80 \%$ in 2011 . In the US, the reported percentages are lower, ranging from $55.3 \%$ in 2010 (wave 3) to $62.7 \%$ in 2008 (wave 1). The lower number in 2010 (wave 3 ) is due to the inclusion of a new younger cohort. The percentages for the ROK rose steadily from $10.9 \%$ to $22.1 \%$ across the three waves as respondents became older, but they are significantly lower than those reported in Japan and the US.

Private pension receivers. As for the data on individuals receiving private pensions, the ROK reported dismal percentages ranging from $3.2 \%$ to $4.5 \%$. On the other hand, JSTAR reported percentages ranging from $12.5 \%$ to $19.4 \%$. The percentages are much higher in the US: around $30 \%$ received private pension in 2006 (wave 1) and 2008 (wave 2) (the $22.7 \%$ figure in the third wave in 2010 is due to the influx of a new, younger cohort).

\footnotetext{
${ }^{8}$ KLoSA uses a slightly different version which we convert to our unified version.
} 
Health Status. HRS used a five-point scale for self-reported health status (from poor to excellent). Both JSTAR and KLoSA included this variable in their questionnaire. Following the literature and our own earlier work, we convert this health status measure into a dummy variable for people whose self-reported status is "good" or "better." Around $80 \%$ of Japanese household heads reported their health being good or better. In the US this percentage is lower at $72 \%-74 \%$. However, only about half of Korean household heads report their health status as good or better. Whether this difference is due to technical issues such as reporting methods or how people assess their health status remains a question, but it may affect our regression results concerning the expected effect of this variable.

Average Household income. As expected, the US has a much higher average income than the two Asian countries. We do see a slightly lower average in the US in 2008 (wave 2) compared with 2006 (wave 1) due to the 2008 financial crisis. Average Japanese household incomes are about half of those of the US while the Korean averages are about one-third of those of the U.S. Note that we use PPP exchange rates to convert nominal figures. For Japan, this exchange rate is typically higher than the nominal market exchange rate. This means that if we use the nominal exchange rate to convert yen to US dollars, the estimated Japanese income variables would be higher than what is reported in Table 3. For the ROK, the opposite is true.

Household wealth (net worth). We construct this variable as the sum of households' net financial and non-financial assets. The former includes stocks, bonds, and other banking accounts (and IRA accounts in the US), while the latter includes households' main residence, other real estate, business assets, vehicles, and other assets. As expected, household wealth is much higher in the US than in the Asian countries, with Japanese and Korean household wealth on average about $60 \%$ and $40 \%$, respectively, of that of the US. Interestingly, even though the Japanese on average hold fewer financial assets than their US counterparts, the percentage of these assets in total wealth is higher. On the other hand, Korean households typically hold less than $6 \%$ of total wealth in financial assets.

Homeownership percentage and value. The first variable is defined by whether the households' current residence value is positive or not. Americans have the highest ownership rate, which is around $80 \%$. It dipped slightly after the financial crisis and the influx of a new, younger cohort to $76.4 \%$, which is still significantly higher than the homeownership percentage in the two other 
Asian countries. The ROK's homeownership rates across the three waves remains quite consistent at just under $60 \%$. However, homeownership rates have changed drastically across waves in Japan. They reached close to $80 \%$ in wave 1 , fell to $63.6 \%$ in wave 2 , and dropped to just $45.4 \%$ in wave 3. We note, however, that new municipalities were introduced in both waves 2 and 3 , so this drop could be the result of survey design as JSTAR is not a random probabilistic survey at the national level.

The second variable - the value of homeownership - exhibits a more consistent level across waves: the US variable features the highest average values while the values across the two Asian countries are steady over the three waves.

\section{Retirement, Pension Dependency, and Wealth Distribution}

In this section, we offer additional detailed analysis regarding the variations of retirement status, working status, income, and wealth among the elderly in the three countries under study. This analysis reveals some additional insights about the sources of the differences across the three countries beyond what we learn from the descriptive statistics.

\section{A. Retirement}

We start with the individual retirement status. The survey question asks respondents to declare whether they consider themselves fully retired. This means that individuals can stay out of the labor force or run their own business or do some voluntary work but still claim that they are not retired. Table 4 reports the percentage of household heads who consider themselves retired in the following age brackets: less than 60; 60-64; 65-69; and 70 and above. The first bracket applies to workers who are below early pensionable ages, except for Koreans during a transition period discussed earlier. The second bracket includes workers in early pensionable ages, while the third bracket applies to people who have reached full retirement age (66 in the US at the time of the survey), and the fourth bracket can be thought of as late retirement age.

[Insert Table 4 here]

Table 4 indicates that more Americans (36.3\%) consider themselves retired compared to workers in the other countries. The two Asian countries' data reveal that a significantly lower 
percentage of workers - around 15\% - consider themselves retired at all three age brackets (the Korean average rose to $20 \%$ in wave 3 due to aging of the only cohort covered in the country's survey). Due to the unique opportunity to retire early in the ROK before reaching the age of 60 , $8.0 \%$ to $9.3 \%$ of Koreans chose to do so, while for Americans this figure is only $3.6 \%$ to $5.8 \%$ due to social security's generous disability programs. Among people who might be eligible for early retirement, $18.2 \%$ to $24.5 \%$ of Koreans chose to retire compared to $22.2 \%$ to $26.1 \%$ of Americans. Among respondents who are in the full retirement age group, 17.1\% to $29.0 \%$ Asians consider themselves retired compared to about half of Americans in this age group (but this figure went down to $47.5 \%$ in 2008 as a result of the financial crisis). For those age 70 and older, the retirement percentages are below $30 \%$ in Japan and $37 \%$ in the ROK, compared to about $70 \%$ in the US.

Because one does not have to claim full retirement to receive pension benefits, it is interesting to compare the percentage of people who stay in the labor force in the three countries. The survey asked whether respondents were working for pay, and the results for the same age brackets in Table 4 are reported in Table 5. Here we see that the percentage of working household heads are quite similar across the three countries in all age brackets. However, among Japanese workers younger than 60 this percentage is above 90\%, although it declines in later waves closer to the percentages seen among workers in the ROK and the US. Surprisingly, the Korean average over all age brackets is lower than that of the US. In the group eligible for early retirement, $61 \%$ of Japanese workers continue to work compared to 55\% of Americans in this group. Koreans belonging to this group work the least, as only $36 \%$ continue working. For the full retirement age group, all three countries have numbers around 30\%. However, 13\% of Americans work well into late retirement age, while only $9 \%$ of Japanese work into their 70s. In later waves (waves 2 and 3), however, the share of Japanese older than 70 who reported working $(23.8 \%$ and $29.1 \%$ for waves 2 and 3, respectively) is higher than in the other two countries. In the ROK, however, only $14.4 \%$ to $16.8 \%$ of Koreans over 70 years old continue to work. Thus, except for wave 1, the two Asian countries' workers retire later in life and continue working well into full retirement age.

[Insert Table 5 here]

\section{B. Public and Private Pensions}

Next, we compare pension coverages for these three countries. We first consider public pensions. Table 6 reports percentages of people receiving public pension by age groups. It is quite 
clear that Japan has the widest public pension coverage among the three countries, while the public pension coverage for the ROK clearly lags behind the other two countries due to the fact that its pension system was developed quite late. For people who are eligible for full public pension, 92.3\% of Americans and $95.8 \%$ of Japanese are covered, while only $30.1 \%$ of Koreans are covered (wave 1). For people age 70 and older, coverage is almost universal in Japan and the US, while only $10.8 \%$ of Koreans in wave 1 and $27 \%$ of Koreans in wave 3 received coverage. Even people in the 60 to 69 age group in the ROK who have a better chance of meeting the eligibility criteria, only around $30 \%$ of them in wave 1 and $50 \%$ in wave 3 reported receiving coverage.

\section{[Insert Table 6 here]}

Table 7 reports coverage rates by age bracket for people receiving private pensions. In this pension category, Americans clearly have a significant advantage over their Asian counterparts. Among Americans in their early retirement age, $29 \%$ receive private pensions. The coverage rates reach $41 \%$ when they reach full retirement ages and it goes to almost $50 \%$ when they are in their 70s. The coverage rates dipped after the financial crisis, as reported in the 2010 wave, but they are still much higher than the coverage rates of their Asian counterparts. For the Japanese, the coverage rates hover around $20 \%$, and only $12.6 \%$ Japanese in their 70 s claimed pension from private sources. For Koreans, the coverages rates are never higher than $9 \%$ across all waves in all the age brackets reported in Table 7. One caveat is that the old income-retirement systems in Japan (before 2001) and the ROK (before 2005) offered lump sum severance payments. It is not clear how these payments have impacted the coverage rates reported in these two countries.

\section{[Insert Table 7 here]}

To assess the degree of dependency on pensions of old-age groups in the three countries in our sample, we first consider the income distribution of the whole sample of old-age groups in each country and those who are fully retired. Table 8 reports this distribution of income at the 10th, 25th, 50th (median), 75th, and 90th percentiles of income. The two tail percentiles (10th and 90th) are included in order to see the impact of pensions on people at the tails of the distribution, which typically have skewed tails. This analysis has potentially important policy implications as well, because those who are most affected by any policy reforms are those in the extreme ends of the spectrum. 


\section{[Insert Table 8 here]}

The median incomes reported in Table 8 for the three countries are somewhat different from the average incomes we report in the summary statistics presented in Table 3. More specifically, the median income for Japan is closer to that of the US. For the whole sample, the median income in Japan is $80 \%$ of that of the US. For people who are fully retired, the gap is even smaller: the median income for that group in Japan is almost $90 \%$ of that of the US. The lower tails are similar for these two countries although the US maintains its advantages over Japan in the upper tails, especially at the 90th percentile, with the Japanese 90th percentile income equal to just $50 \%$ of US income in the whole sample, and two-thirds in the fully retired subsample. This clearly is the driving force behind the average income gap between these two countries.

For the ROK, both the median income and the average income are about one-third of US median and average income, respectively. However, the lower tail looks very different from that of the US. The whole lower tail of the Korean income distribution is close to 0 , which is also the case for the fully retired subset. At the same time, Table 8 indicates that the ROK has managed to narrow the gap in the upper tail of the income distribution compared to the US relative to the larger gap in the lower tail. The 90th percentile income is $44 \%$ of that of the US for the whole sample and the fully retired subsample. The fat right tail of the income distribution in the ROK is quite striking: the median income is only one-third of the upper quartile for the whole sample while the median income for the fully retired is only one-tenth of the upper quartile. It seems that many Korean retirees have to resort to their savings to support their consumption.

The median percentage of total income received from total pension income can be used as a rough measure of dependency on pension income during retirement. Because relatively few Asians would claim they are fully retired, we calculate the median percentage for people over the age of 65. However, while public pension coverage in both Japan and the US is almost universal for this age group, there is still limited pension coverage (well below 50\%) for Koreans in the same group. For this reason, Table 9 compares the median percentage of income received from pensions just for Japan and the US. We compute it for all the age groups above 65 in our sample and also break it down by income quartiles.

[Insert Table 9 here] 
Table 9 shows that for Americans over age 65, 85.7\% of their retirement income comes from public and private pensions. For the Japanese in the same age group, however, only $77.3 \%$ of retirement income comes from public and private pensions. This evidence implies that the US has a more rewarding retirement system than Japan. At the same time, to the extent that most of the pension coverage comes from public pensions, our finding implies that Americans rely on the public pension system more than their Japanese counterparts. Indeed, Table 9 shows that people at the lowest income quartiles, on average, rely entirely on pension income, and those in the second lowest quartiles rely heavily on pension income as well. For those whose incomes are in the third quartile, however, more than one-quarter of their incomes come from sources other than pensions. For people in the highest income bracket, the median percentage coming from non-pension sources is only $63 \%$. In sum, we can say that three-quarters of people in both the US and Japan rely heavily on the retirement pension system for their old-age income. Even wealthier people (in the highest quartile) derive a substantial portion of their incomes from the pension system.

\section{Wealth, Financial Wealth, and Stock Ownership}

The previous section, which focused on the extent to which old-age income in the three countries is dependent on the existence of private and public pensions, raises a question about the role of accumulation and management of private savings as an additional channel which affects the financial well-being of individuals and households. The question is important because if the majority of people derive their income just from the pension system, especially if the latter is in the form of defined benefits rather than defined contributions, such dependency limits the opportunities for older and retired people to cope with unforeseen financial and health predicaments affecting themselves or their family members. Since high degrees of dependency on pension income are the result of insufficient private wealth accumulation, we explore in this section the distribution of personal wealth in the three countries under study.

Table 10 reports the distribution of household net worth at the 10th, 25th, 50th (median), 75th, and 90th percentiles in thousands of 2010 US dollars (see Section III for a definition of household net worth) for the whole sample of older age groups as well as the fully retired in our three countries. A quick overview indicates that Japan and the US share similar wealth distributions, especially for the whole sample. The Korean wealth distribution is quite different, 
however, and resembles to a large extent the country's income distribution, which immediately indicates the large influence of private and public pensions in the country.

[Insert Table 10 here]

While the Japanese wealth distribution is thicker in the lower half of the distribution and even at its median in wave 1, the American wealth distribution is thicker in the upper half, which clearly dominates the distribution. Looking only at those who are fully retired, the American distribution dominates the Japanese over the whole distribution and across all waves. The same applies to the comparison between the American and the Korean distributions. Just like the income distribution, the wealth distribution of the ROK is heavily skewed and wealth accumulation seriously lagging that of other developed countries. This is largely the result of higher human and physical capital accumulation in the US relative to the two Asian countries in recent centuries. The obvious implication is that Americans enjoy a higher level of retirement income relative to their Asian counterparts. An interesting question to ask is to what extent is this the result of private accumulation of assets as opposed to the private and public pension systems in the three countries.

We are tempted to think that the larger accumulation of wealth in the US might be due to their relatively large holdings of stocks and financial assets. However, as reported in Table 11, this conjecture is not entirely correct. Looking at the whole sample, the Japanese almost dominate the Americans over the entire financial wealth distribution. Moreover, it is surprising to see that the median value of financial assets in Japan is almost five times higher than that of the US. Even for people who are fully retired, the median value of financial assets in the US is almost half of that in Japan. Americans do hold more financial assets, however, in the upper tail-the 90th percentile of the whole sample - and even in the two upper quartiles of the financial wealth distribution of the fully retired in wave 1. Koreans hold far fewer financial assets compared with these two countries. Even the value of financial assets at the 90 th percentile in the ROK is just $60 \%$ of the median value in Japan. This should not be a total surprise because economic development in the ROK started much later than in Japan. But it is still odd to see that more than half of Korean households do not hold any financial wealth.

[Insert Table 11 here] 
We turn next to stock ownership in all three countries as reported in Table 12. Following the conventional definition, this classification includes both direct stock ownership and or indirect ownership through other financial instruments such as mutual funds. This category excludes pension plans, even those based on DC plans, according to the way the survey questionnaire is structured. The overall stock ownership in the US is around $30 \%$, which means $30 \%$ of American households hold some form of stocks, while in Japan stock ownership experienced a sharp increase from 13\% in 2007 (wave 1) to over 20\% in 2011 (wave 3). Stock ownership in the ROK, however, is almost negligible - in all survey years, less than 5\% of Korean households reported owning stocks. Table 12 shows, however, that stock ownership rises when we restrict the sample to include only households that report positive overall wealth and positive financial wealth. In the latter group, stock ownership reaches almost $40 \%$ of all US households. It also increases to around 15\% in waves 1 and 2 for Japanese households with positive financial wealth, and shoots up to $24 \%$ in wave 3.

\section{[Insert Table 12 here]}

The data on stock holding can provide an explanation as to why Americans hold more financial assets in the upper tails of the distribution of financial assets. The driving force behind the thick upper tails of the distribution is stock ownership, due to the higher expected values of stocks relative to fixed-income assets. The median value of personal stocks in the US is $\$ 70,300$ in 2006 (wave 1), 2.6 folds higher than the median of \$26,200 in Japan. This gap between the US and Japan stays the same even in 2010-2011 (wave 3) when stock ownership rate in Japan increases dramatically to $24 \%$. The median value of personal stocks in the ROK is only $\$ 14,000$ in 2006 (wave 1). Comparing the fully retired households with households in the whole sample, we see an increase in stock ownership by retirees in the US and Japan (except in wave 1), while stock ownership becomes smaller for retirees in the ROK. However, in all three countries, the median retiree holds a higher value of stocks than the median household in the whole sample.

The policy ramifications from our analysis of stock ownership are quite clear. If more American households were willing to hold stocks, then they would be likely to hold more financial wealth and total wealth over the entire wealth distribution relative to Japanese households. The lesson from this analysis especially for Korean households and policy makers appears to be that households may gain significantly from policies promoting stock ownership in the ROK. The 
lesson may have already started to sink in: in recent years, some financial reports have indicated that the overall stock ownership by Koreans has started to crack the $10 \%$ barrier. But this pace of increase may not be fast enough to improve the country's wealth distribution, especially among current or soon-to-be retirees, to a level comparable to that of Japan and the US.

\section{The Asset Management Model and Participation in Risky Asset Holding}

Given the apparent importance of the contribution of stock ownership to the accumulation of financial wealth and overall wealth, and thus the promotion of financial well-being for retirees, this section focuses on the determinants of participation in stock ownership. This is a wellresearched topic in the literature. Traditionally, however, the approach used in the household finance literature to explain this issue (see, for example, Campbell 2006) has tended to focus on preferences and bequest motives as well as underlying income and savings constraints, or the role of financial literacy. Ehrlich, Hamlen, and Yin (EHY) (2008) and Ehrlich, Shin, and Yin (ESY) (2011) develop a labor-theoretic model of asset management based on noisy rational expectations (Grossman and Stiglitz 1976, Verrecchia 1982) and the determinants of productive savings through asset management (Ehrlich and Ben-Zion 1976). Our point of reference is what we call "the asset management hypothesis" (AMH). We present the outline of this approach and implement it empirically by following the econometric model that Ehrlich and Yin (2021) developed to analyze the HRS data from the US. We then modify this model to apply to all three datasets used in our current study. The value added of this application of the AMH lies not only in a comparative analysis across countries but also in a decomposition analysis we pursue empirically to determine the separate contribution of individual asset management relative to the distinct contribution of financial markets within which individuals manage their assets. This decomposition analysis is similar to the method used in labor economics to address racial or gender gap.

\section{A. The Asset Management Hypothesis}

The standard assumption in the finance literature that equilibrium prices of financial assets are "fully revealing" of all relevant information on the performance of these assets raises a puzzle at the micro level: it leaves no incentive for individuals to collect any private information (see, for example, Grossman and Stiglitz 1976). But how, then, do prices become fully revealing? To 
resolve this puzzle, it seems necessary to augment the equilibrium theory of efficient markets with complementary micro foundations. In the context of centrally traded homogeneous assets, the idea is that the public information revealed by market prices is incomplete or imperfect even in equilibrium, leaving room for at least some asset management activity by heterogeneous investors endowed with different abilities, opportunities, and prior knowledge.

The asset management hypothesis, as formulated by EHY (2008), for example, is a natural extension of the "costly information" or "noisy prices" literature. In extending the basic framework of the "noisy" rational expectations model (see, for example, Verrecchia 1982), EHY specify a precision production function of a Cobb-Douglas type, which is a function of one's human capital and time spent on information acquisition. By developing market equilibrium properties associated with imperfectly informed markets, the EHY and extended models yield solutions for the optimal demand for investment in information precision, based on both market and private signals, and the associated expected individual demand for alternative risky assets, as well as the resulting overall portfolio returns.

In particular, the theoretical models lead to an explicit reduced form specification of the determinants of the expected demand for a risky asset (RA), which stems from greater demand for asset management activity, that is, gaining private information about the productivity of traded assets. Such activity can be shown to enhance the expected demand for risky asset holding due to a more precise assessment of the riskiness of these assets. Modified to account for asset management by those approaching retirement age or retirees, the reduced-form regression can be outlined as follows:

$$
E(R A)=\Omega(H C, H, w, F A)
$$

In equation (1), $E(R A)$ is the expected demand for risky assets. $H C$ is human capital (or knowledge), either general or specific, which in turn can be modeled as a function of schooling $(S)$ and experience $(\operatorname{Exp})$, or $H C=f(S, \operatorname{Exp}) ; H$ stands for individual health, both physical and mental, which can be taken as a constraint on productive time that can be devoted to asset management; $w$ denotes the opportunity cost of asset management time, usually proxied by the wage rate; and $F A$ denotes investor's accumulated portfolio size - a proxy for experience in managing assets and lower fixed costs of entry to risky markets due to scale economies. 
We do not explore the role of the wage rate in our current regression analysis because this information is not reported in the sample of older workers who are still active and is naturally absent in the sample of fully retired workers who earn no wages during their retirement phase. Partly because of this fact, we expect that general education, which raises efficiency in managing assets as well as one's wage earnings power, will tend to have an unambiguous positive effect on asset management and the expected demand for risky assets, E(RA), especially in the case of retired persons. More generally, the regression results reported in EHY (2008) and ESY (2011) indicate that the impact of education on asset management efficiency exceeds that of the opportunity cost of asset management time, which should be the case especially for retirees who earn no wages.

From this expected demand for $R A$, we also derive an expected portfolio return equation:

$$
E(\text { Portfolio Return })=\Psi(S, \text { Exp, } H, w, F A)
$$

The asset management hypothesis thus implies that investors in general, including older workers and retirees who have higher educational attainments and are in better health, will be more efficient in managing risky portfolios and thus more willing to participate in (enter into) the market for risky assets. By participation we mean willingness to hold at least some risky assets in their financial portfolios, which can be best proxied by stocks $(R A>0)$. The hypothesis also implies that people with higher education or better health would tend to have a larger expected demand (i.e., average demand over the long term) for risky assets, and thus allocate a larger percentage of their portfolios to risky assets. Such tendency to manage, rebalance, and hold more risky securities ultimately yields a higher corresponding market return for individuals with more education and better health, independently of their attitudes toward financial risks.

Note, however, that the hypothesis does not imply that asset management directly affects the returns on the observed risky market portfolio, comprised of just risky securities. The return on any risky asset held is determined strictly by the market in which it is traded. However, higher general and specific knowledge and better health enable investors to assess risk more accurately and select and rebalance efficient portfolio compositions, for example, when portfolios include securities that are traded in different international markets. Therefore, these investors have, on average, a greater demand for or a larger portion of risky assets in their financial portfolios (ESY 2011). A more informed selection of risky assets can thus yield higher returns on individuals' 
overall financial portfolios by increasing the share of the risky assets in a portfolio comprised of both stocks (including risky corporate bonds) and fixed-income assets.

\section{B. Empirical Implementation}

We implement the basic ideas of the asset management hypothesis by using the three longitudinal datasets described in the preceding sections, with particular emphasis on the role of educational attainments and health status in enhancing the expected demand for stocks due to better information and physical and mental health, which enhances effective asset management. We concentrate on the participation decision due to data limitation. In addition, some of the demographic variables used in Ehrlich and Yin (2021) are available only in HRS, such as race and cohort. The regression specification we use to implement the basic decision variables in our model is thus given in equation (1a) as follows:

$$
\begin{gathered}
\operatorname{Pr}(\text { Rah }=1)=a_{0}+a_{1} \text { Age }+a_{2} \text { Age } e^{2}+a_{3} \text { Education }+a_{4} \text { Health }+a_{5} \log (\text { income })+a_{6} \\
\log (\text { wealth })+a_{7} \text { Gender }+a_{8} \text { Coupled }+a_{9} \text { Retired }+a_{10} \text { PrivatePension }
\end{gathered}
$$

The dummy variable, Rah, is an indicator of whether the household holds any stocks, as reported in the three surveys. We choose educational attainment as an education proxy because continuous years of education are not available in JSTAR and KLoSA. Health is a health-status index, based on the individual's self-reporting, indicating whether the self-reported health is good or better. Income is household income while wealth is household net worth (see Section III for definitions). Gender is a dummy variable which is 1 for male and 0 for female, while coupled and retired are dummy variables to distinguish couples that are living in a household and heads of household who consider themselves retired. Finally, Private Pension is a dummy variable indicating whether households receive any private pension. A complete definition of these variables is given in Section III.B.

We run a probit regression analysis of equation (1a) using the HRS, JSTAR, and KLoSA data on households with positive survey weights, positive wealth (due to the need to do logarithmic transformation on this variable), and household heads older than 50. The results are reported in Tables 13-15 for all three waves. The regression results are quite robust across the three waves. 
In what follows we therefore focus on largely on the results obtained across the three samples based on the 2006-2007 wave.

\author{
[Insert Table 13 here] \\ [Insert Table 14 here] \\ [Insert Table 15 here]
}

\title{
C. Regression Results
}

A quick inspection of the results across the three samples in Tables 13-15 indicates that the probit regression specification yields the most robust results using the HRS sample, where all coefficients are statistically significantly at 5\%, the only exception being the coefficient of age, which is significant at the $10 \%$ level. In the probit analysis using JSTAR and KLoSA, some of the demographic variables become insignificant, in particular gender, coupled, and retired.

The most important result of our probit analysis is that it verifies the key proposition of the asset management hypothesis: the educational attainment of the household head has a statistically positive and significant impact on the probability that households will be holding risky assets, which in this application are represented by stocks. We observe this significant effect of education across all countries as well as across all waves within the three countries, with no exception.

Due to the nonlinearity in the probit model, it is difficult to assess the quantitative impacts of educational attainments on participation solely based on regression results. To generate a quantitative measure of the difference in participation, we compare the participation probabilities across households attaining high school education versus some college education. We make sure that the two groups are identical, except for their different educational attainments, by assuming that all their other characteristics follow the sample-weighted averages. For the 2006-2007 wave, the differences in the probability of holding risky assets between these two groups are $7.96 \%, 7 \%$, and $5.42 \%$ in the HRS, JSTAR, and KLoSA, respectively. Turning into percentage differences, a higher educational attainment would boost stock ownership by $21.53 \%, 27.30 \%$, and $34.56 \%$, respectively. ${ }^{9}$

\footnotetext{
${ }^{9} \mathrm{We}$ did this comparison for other waves as well, using the corresponding data sets, and found comparable results.
} 
Our secondary conjecture, that better health would more likely lead people to own stock, is verified only by our regression analysis using HRS data. This variable becomes insignificant in both JSTAR and KLoSA. A possible reason is that the health variable is a subjective measure of how well people perceive their health to be, and these perceptions may differ across countries. In Japan, as we see in the descriptive statistics, most people rate their health status to be quite high. The opposite seems to be the case in the ROK (see descriptive statistics in Section III.B). The sharply divergent concentrations of the individual data may bias the regression coefficient associated with the health dummy downwards. The lower participation rate in stock holding might bias the impact of health as well since, as a proxy for productive asset management, it becomes less relevant.

The total effect of the age variable is found to be U-shaped in the HRS regressions. But the age effect is not symmetrical across waves in the Asian countries: it is hump-shaped in Japan (in wave 1), U-shaped in the ROK (in waves 1 and 2), and flat in other waves (in Japan in waves 1 and 2 and in the ROK in wave 3). The U-shaped age effect in the HRS regressions means that older people tend to hold stocks. We compute the age at which older US investors start raising their stock holdings to be around age 60, 59.4, and 64.9 in the 2006, 2008, and 2010 waves, respectively, which is reasonable since at this age wealth accumulation becomes more substantial for most households, although this may be the case mainly in the US.

Income is included merely as a control variable. Without its presence, the education effect might mistakenly pick up its explanatory power. Its positive coefficient is statistically significant in regressions using HRS and JSTAR data. In contrast, wealth is included as an efficiency measure, since it may represent experience at managing assets. Its positive impact is statistically significant in all regressions.

In regressions based on the HRS sample, both retirement status and having private pension as income have a statistically positive impact as well. This might be an indication of the presence of spillover effects from having pension funds, especially those based on defined contributions or IRAs, since individual account holders have a direct responsibility for making decisions about portfolio composition in such funds. However, the market for such funds appears to be weaker in Japan and especially in the ROK.

\section{Decomposition}


How much of the difference in observed stock ownership is due to the difference in the structure and efficiency of the financial markets that is separate from the effect of individual characteristics? Christelis et al. (2013) used a method originally developed in labor economics to assess the distinct effect of the labor market environment in explaining the impact of gender on the entire distribution of wage earnings. Christelis et al. used this method to assess the effect of what they call the "environment" on wealth distribution as well as on all asset ownership.

Basically, the difference in participation rates $(p r)$ between the base country and country $i$ can be decomposed as follows:

$$
p r^{\text {base }}-p r^{i}=\left\{p r^{\text {base }}-p^{i, b a s e}\right\}+\left\{p^{i, b a s e}-p r^{i}\right\}
$$

where $p^{i, \text { base }}$ is the predicted stock ownership for country $i$ if people in that country move to live in the base country. In other words, it is the counterfactual stock ownership of households in country $i$. The first difference term on the right side of equation (3) can thus be thought of as the covariates effects, because it illustrates the difference in the observed stock ownership when people in both countries are facing the same coefficients, or the same environments, in the base country. The second difference term on the right side of equation (3) signals the coefficients effects, because it is the difference between the counterfactual ownership rates for country $i$ and the actual ownership rates in that country. This difference can be interpreted as the effect of the efficiency of the financial (including pension) market on the difference in the observed household participation rates in holding stocks.

We apply this decomposition method to all waves of our three micro datasets by using the US as the base. The results are reported in Table 16.

\section{[Insert Table 16 here]}

Our first observation is that all decomposition effects are statistically significant at the 5\% level. It is interesting to see most of the differences due to both the covariates and institutional effects have positive signs, the only exception being the difference due to the coefficients effect in JSTAR in 2011. In other words, the observed difference in the participation rates, which indicates that the US has a higher participation rate than the Asian countries, is due to two factors: i) the higher level of key explanatory variables in US relative to the two Asian countries, such as 
education and wealth; and ii) a financial market environment in the US that is more accommodating to participation than in the other Asian countries.

Another major observation is that the magnitudes of the differences are generally larger in the ROK than in Japan. Furthermore, the relative weight of the covariates effects vs. the financial markets efficiency effects vary between Japan and the ROK. In Japan, the weight of the independent effects is more equal than in the ROK. This implies that the financial market effect has more weight in the ROK relative to Japan in explaining the participation gap in the ROK relative to the US.

The difference due to covariates are very robust for both countries across waves. They vary from $7.72 \%$ for Japan in wave 1 to almost $10 \%$ in wave 2 and $9.16 \%$ in wave 3 . For the ROK, this difference steadily decreases from $20.78 \%$ in wave 1 , down to $17.15 \%$ in wave 2 , and further down to $15.85 \%$ in wave 3 . The explanation for the decline in the ROK is quite straightforward. The most powerful driving force in stock ownership is the household's net worth, and we see a gradual, albeit slow rise in net worth in ROK over this time period relative to the US."

As for the difference in the effects of the financial market environment on participation, we observe a widening gap in the ROK: the difference due to coefficients grows from $7.43 \%$ in wave 1 to $8.90 \%$ in wave 2 and further expands to $11 \%$ in wave 3 . This might be a result of a combination of improvement in institutional arrangement in the US (more DC plans encourage more stock ownership) and a lagging development in institutional arrangement in the ROK (slow development of the stock market and modernization of private pension plans). This pattern needs to be further analyzed in future research.

In Japan, we see a quick reversal of the difference in the impact of the financial market efficiency on participation-while this difference accounts for almost half of the total difference in wave 1 at $8.24 \%$, it narrows to $5.24 \%$ in wave 2 , and then turns negative at $-4.65 \%$ in wave 3 . The negative difference in 2011 means that Japan now holds an advantage in pension market efficiency relative to the US, which encourages stock ownership. Whether this interpretation is valid, however, requires further research. This is because there are several factors that may lead to this interpretation. One factor is that survey design JSTAR is not a national probabilistic survey, 
and it added new municipalities in both waves 2 and 3. So the reversal in apparent market productivity may merely reflect the difference between the newly added municipalities and the old ones. Another possible explanation is that by 2011 private pension plan reforms that were introduced by 2001 in Japan may have begun bearing fruit. We leave this issue to further research.

\section{Conclusion}

In this paper, we attempt to estimate the degree of financial readiness of older cohorts in two relatively developed Asian countries by identifying the main channels affecting their financial readiness or government dependency and assessing their relative importance through a comparative analysis within and across the two countries and in comparison to a reference country. We selected Japan and the ROK as representatives of the Asian countries and added the US to serve as a reference point for both for two reasons: all three countries have conducted similar micro-level longitudinal surveys of the financial wellness and health of elderly individuals and households using the same survey methodologies. These surveys report information on the three main channels of old-age support for older households and retirees: the income benefits they derive from the public and private pension systems in their corresponding countries and the accumulated values of their households' total and financial assets. The latter channel allows us to study the extent to which households' wealth and asset management contribute to their own financial readiness at old age. Also, all countries have experienced a demographic transition that has tended to accentuate the degree of dependency of older and retired cohorts on old-age financial support systems in their respective countries. The rapid aging of the populations, especially in Japan and the ROK, makes the analysis of the determinants of the households' financial readiness during their retirement a topic of academic importance and policy relevance.

To compare of the strength of old-age support systems in the three countries, we first looked at the macro environments in these countries to determine the extent to which demographic transitions have affected these countries' old-age dependency ratios. We find that the two Asian countries, especially the ROK, are facing an increasing overall level of dependency on both their public and private pension systems due to rising life expectancies along with sharply declining total fertility rates relative to the US. These demographic trends raise serious potential challenges to the financial viability of old-age retirement systems in the Asian countries relative to the US. 
We then briefly assessed the retirement income systems in these countries, including both the public and private pension systems. Japan and the US have a clear advantage over the ROK in terms of the financial strengths of their pension systems, not only because they are more developed but also because they were established much earlier than the Korean systems. Although the public pension systems in Japan and the US are comparable in terms of their current financial viability, we find that US households obtain higher benefits from their private pension system compared to their Japanese and Korean counterparts, and their private pension system is better funded as well. In contrast, the Korean private pension system is much weaker.

We examined the three countries further by studying the extensive personal and financial household data provided in their micro-level longitudinal surveys - the HRS, JSTAR, and KLoSA surveys - to further analyze the differences among the three countries in terms of their old-age financial readiness. We find that Americans typically retire earlier than their Asian counterpartsboth Japanese and Koreans workers tend to work into their 70s, whereas more American retire at their early and full pension-eligible ages. We also find that the replacement rate of income in retirement are comparable in Japan and the US for retirees earning average incomes, while Koreans have much lower replacement rates.

Using our micro-level data, we were also able to construct aggregate distributions of income, net worth, and financial assets for the three countries. While the US dominates both countries in all distributions, it only dominates Japan at the upper part of their respective distributions of net worth and financial assets. The corresponding net worth and financial wealth in the ROK lags significantly behind those of the other two countries.

Turning finally to the extent to which individuals and households contribute to their own financial readiness through their accumulated savings and asset allocation decisions, we examine the role of a key determinant of wealth accumulation and old-age financial readiness in developed countries: stock ownership. To determine the extent to which this private source of old-age financial well-being is functioning in the three countries, we implement the asset management model of the demand for risky assets developed in EHY (2008). Specifically, we conduct a probit analysis of stock ownership using the data on individual-level characteristics of household heads that are expected to contribute to the willingness to hold stocks. 
Our empirical analysis strongly confirms the key proposition of our model. The regression results we obtain, using samples of older-age cohorts and retired cohorts in each of the three countries and all wave samples within each country, show that educational attainments of household heads and household wealth accumulation exert a significant positive effect on the willingness of the households to hold stocks in their financial portfolios. In addition, we utilize an econometric model to decompose the total gap in stock ownership across countries into the portion that is attributable to differences in the individual characteristics of investors and the portion that is due to the differences in the level of development of the financial markets and pension systems that exist in the respective countries. We find that much of the total difference in stock holding between Korean, and to some extent Japanese, households and their US counterparts is attributable to differences in the household's individual characteristics. However, our decomposition analysis also shows that a large part of the gap in stock ownership is attributable to the institutional characteristics of the different financial systems, largely because of the level of development of the private pension sector in the Asian countries, especially in the ROK relative to the US. A more encouraging finding from this analysis is that the difference in the institutional characteristics of the pension systems between the US and Japan, and to some extent even the ROK, have started shrinking in later waves of the households' individual longitudinal surveys we explore. Whether this trend will continue going forward may be a subject of future research.

Our model suggests that the significant contributions of household asset management and the level of development of the pension systems in the three countries to the willingness of investors to hold stocks and other risky assets are expected to enhance portfolio returns as well (for concrete evidence see Ehrlich and Yin [2021] and Ehrlich and Shin [2021]). Our findings thus offer important policy implications on the way the financial readiness of older and retired cohorts can be improved in all surveyed countries, especially in the ROK. This is achievable through a faster development of the markets for private pensions as well as via a concerted effort to use special education programs to raise the financial knowledge of older age groups. In future research we plan to further explore more specific policy reforms based on our findings, which might help improve the financial readiness of older age groups and lower their dependency on the public support systems in their respective countries.

\section{References}


Campbell, John. 2006. “Household Finance.” Journal of Finance 61 (4): 1553-1604.

Dimitris Christelis, Dimitris Georgarakos, and Michael Haliassos. 2013. "Differences in Portfolios across Countries: Economic Environment versus Household Characteristics." The Review of Economics and Statistics 95(1), 220-236.

Ehrlich, Isaac, and U. Ben-Zion. 1976. "Asset Management, Allocation of Time and Returns to Savings." Economic Inquiry 14(4), 558-586.

Ehrlich, Isaac, and Jinyoung Kim. 2005. "Endogenous Fertility, Longevity, and Economic Dynamics: Using a Malthusian Framework to Account for the Historical Evidence on Population and Economic Growth." Journal of Asian Economics, 15(6), 789-806.

Ehrlich, Isaac, and Jong Kook Shin. 2021. "Can Human Capital and Asset Management Improve the Financial Performance of Older Age Groups? Evidence from Europe.” (report to ADB)

Ehrlich, Isaac and Jong Kook Shin, 2010. "Human Capital and Imperfectly Informed International Financial Markets", American Economic Review, 100(2), 244-249.

Ehrlich, Isaac and Yong Yin. 2021. "The Role of Asset Management, Education, and Health in Financial Decisions of Older Adults." (Report to ADB)

Ehrlich, Isaac, William A. Hamlen, and Yong Yin. 2008, "Asset Management, Human Capital, and the Market for Risky Assets." Journal of Human Capital 2 (3): 217-62.

Ehrlich, Isaac, Jong Kook Shin, Yong Yin. 2011. "Private Information, Human Capital, and Optimal ‘Home Bias' in Financial Markets.” Journal of Human Capital 5 (3), 255-301.

Grossman, Sanford, and Joseph Stiglitz. 1976. "Information and Competitive Price Systems." The American Economic Review 66 (2): 246-53.

Ichimura, H., S. Satoshi, and H. Hideki. 2009. JSTAR First Results 2009 Report. Research Institute of Economy, Trade and Industry (RIETI).

Juster, F. Thomas and Richard Suzman. 1995. "An Overview of the Health and Retirement Study.” Journal of Human Resources 30: S7-S56.

OECD. 2009. OECD Private Pensions Outlook 2008. Paris: OECD Publishing. 
. 2019. Pensions at a Glance: OECD and G20 Indicators. Paris: OECD Publishing.

. 2020a. Pension Funds in Figures. Paris: OECD Publishing.

. 2020b. "Purchasing Power Parities (PPP)." doi: 10.1787/1290ee5a-en (accessed October $29,2020)$.

Rajnes, David. 2007. "The Evolution of Japanese Employer-Sponsored Retirement Plans." Social Security Bulletin 67 (3).

Social Security Administration. 2008, 2018. Social Security Programs Throughout the World: Asia and the Pacific. SSA Publication.

United Nations. 2019. "World Population Prospects 2019." Population Division, Department of Economic and Social Affairs. https://population.un.org/wpp/ (accessed September, 3, 2020).

Verrecchia, Robert. 1982. "Information Acquisition in a Noisy Rational Expectation Economy." Econometrica 50 (6): 1415-30.

Venti, Steven F., and David A. Wise. 2001. "Choice, Chance, and Wealth Dispersion at Retirement." In Aging Issues in the United States and Japan, edited by Seiritsu Ogura, Toshiaki Tachibanaki, and David Wise, 25-64. Chicago: University of Chicago Press. 
Figure 1. Total Fertility Rates: 1955-2040

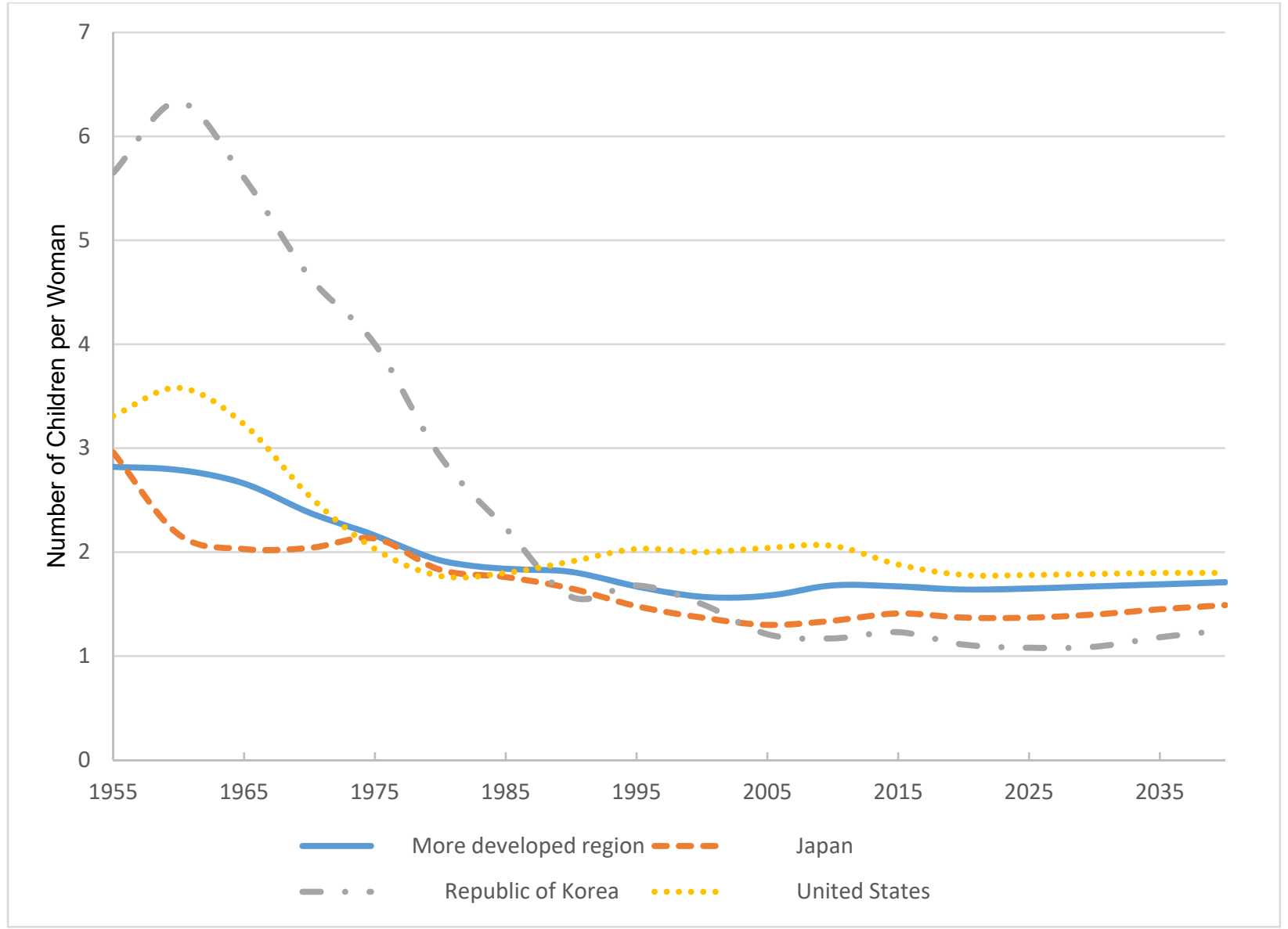

Source: United Nations. World Population Prospects 2019. https://population.un.org/wpp/ (accessed September 3, 2020). 
Figure 2. Life Expectancy at Age 65: 1955-2040

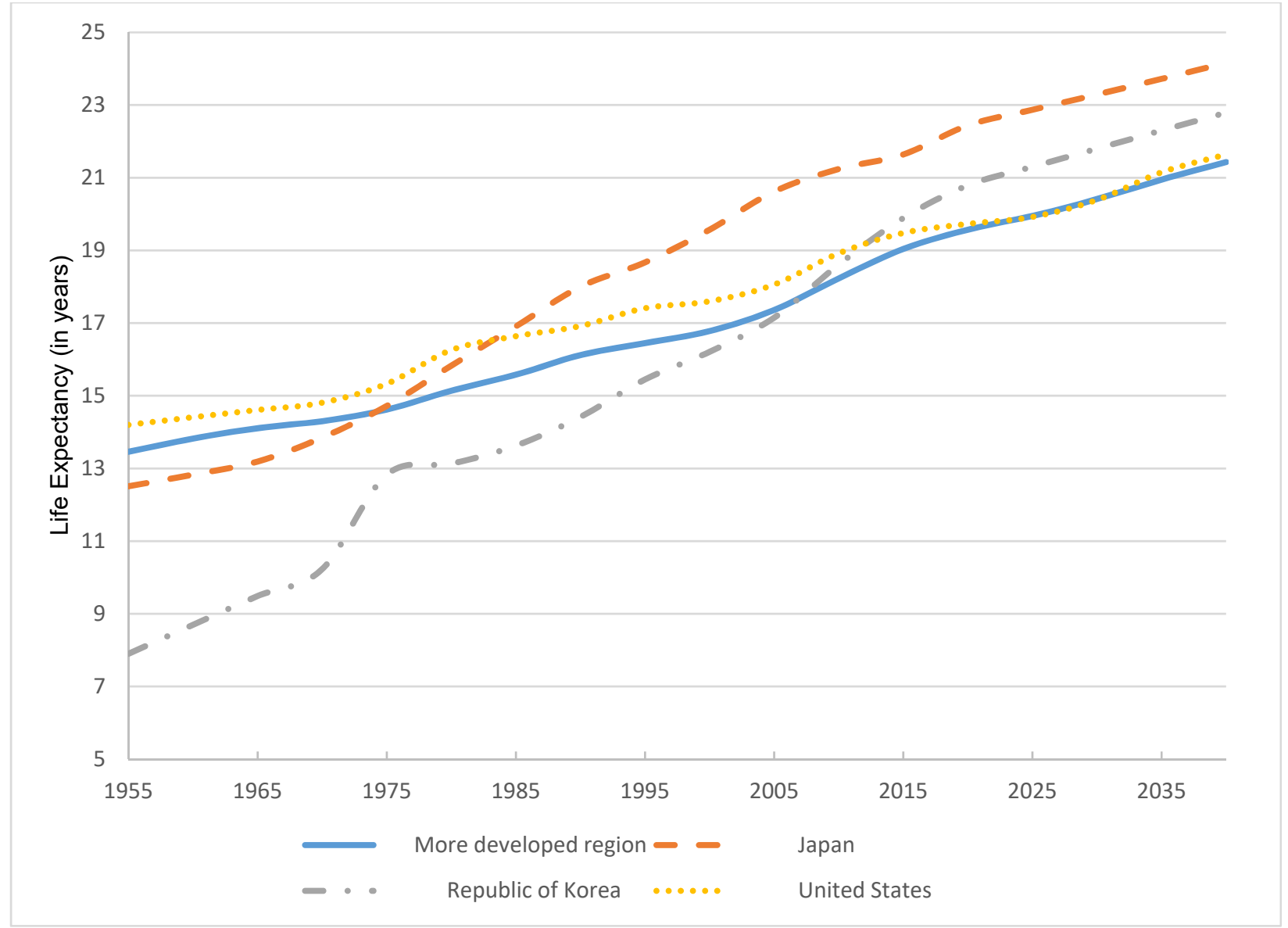

Source: United Nations. "World Population Prospects 2019." https://population.un.org/wpp/ (accessed September 3, 2020). 
Figure 3. Demographic Old-Age to Working-Age Dependency Ratio: 1950-2040

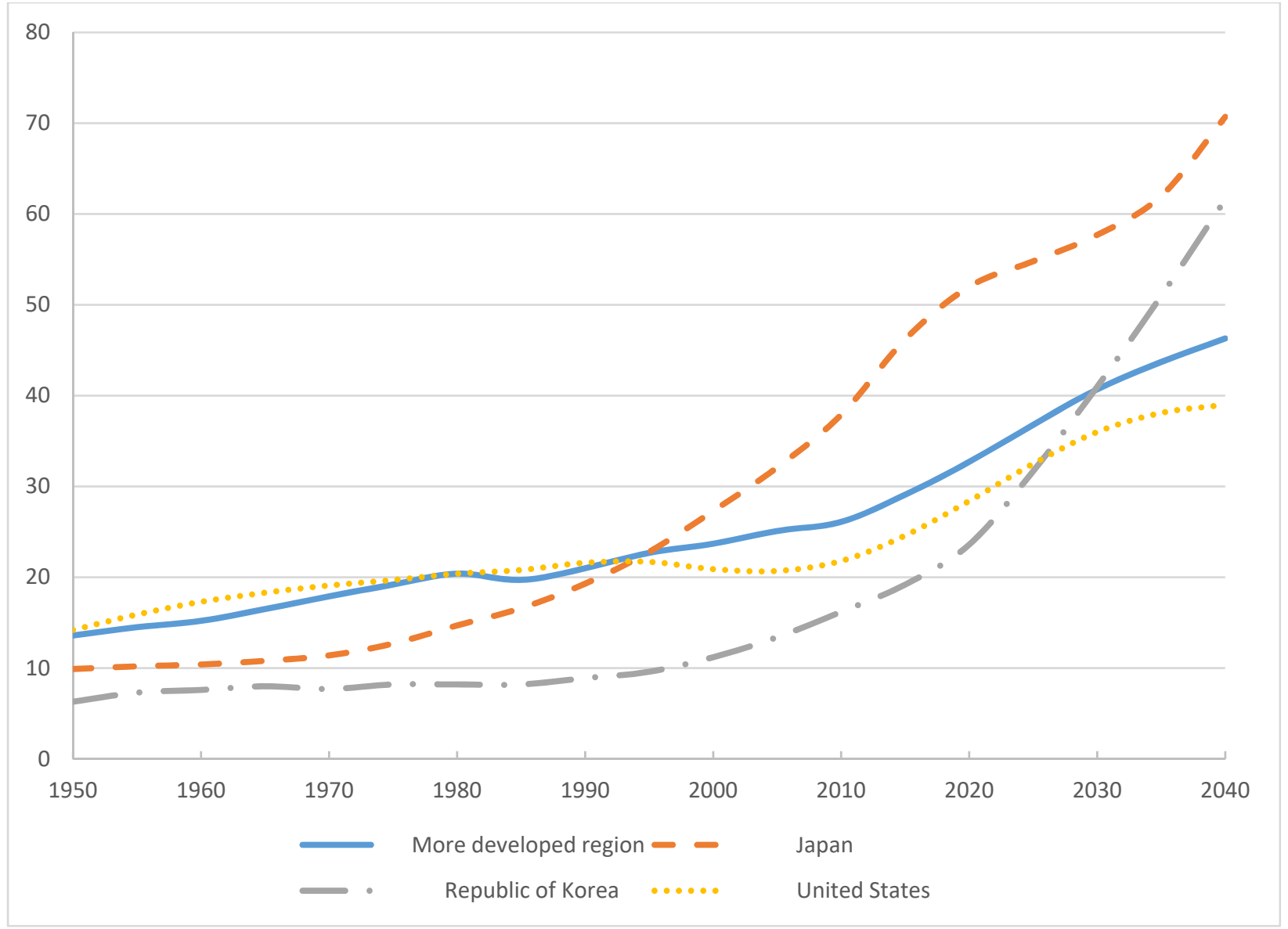

Note: The ratio is defined as the number of individuals age 65 and over per 100 people between age 20 and 64.

Source: United Nations. "World Population Prospects 2019." https://population.un.org/wpp/ (accessed September 3, 2020). 
Figure 4. Life Expectancy at Birth: 1955-2040

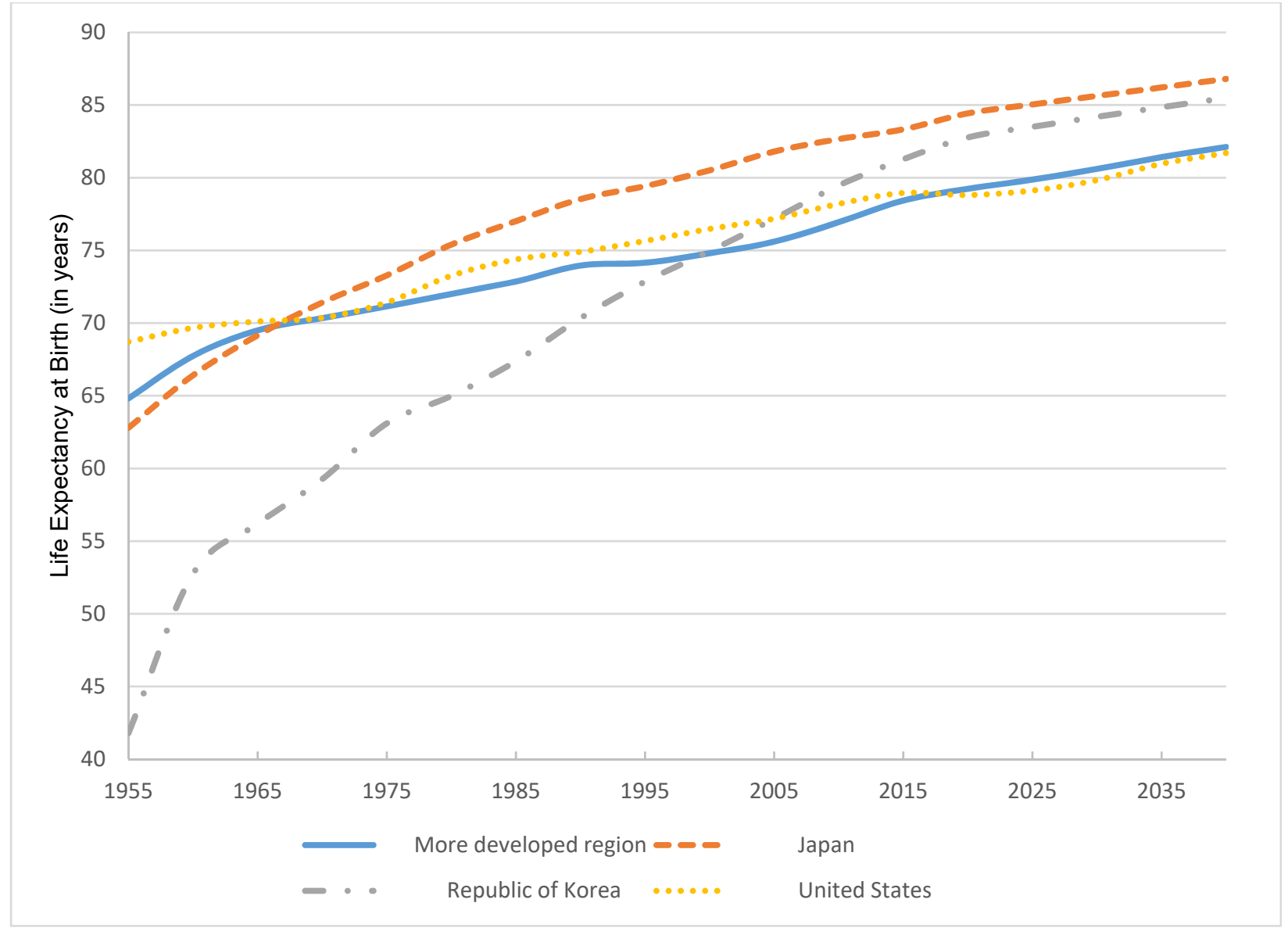

Source: United Nations. "World Population Prospects 2019." https://population.un.org/wpp/ (accessed September 3, 2020). 
Table 1. Net Pension Replacement Rates of Earnings for Workers Earning Multiples of Mean Earnings

\begin{tabular}{|c|c|c|c|c|}
\hline Country & Pension Age & \multicolumn{3}{|c|}{ Replacement Rates of Individual Earnings, by Multiples of } \\
& & \multicolumn{3}{|c|}{ Mean Earnings } \\
\hline & & $\mathbf{0 . 5}$ & $\mathbf{1}$ & $\mathbf{1 . 5}$ \\
\hline Japan & 65 & 45.9 & 36.8 & 33.3 \\
\hline Republic of Korea & 65 & 60.8 & 43.4 & 32.6 \\
\hline United States & 67 & 61.2 & 49.4 & 42.7 \\
\hline OECD & 66.1 & 68.3 & 58.6 & 54.7 \\
\hline
\end{tabular}

OECD = Organisation for Economic Co-operation and Development.

Source: OECD pension models, as reported in OECD (2019).

Table 2. Wave, Year, and Number of Units

\begin{tabular}{|c|c|c|c|}
\hline & HRS & JSTAR & KLoSA \\
\hline Wave & 8 & 1 & 1 \\
\hline Year conducted & 2006 & 2007 & 2006 \\
\hline Number of units with positive weights & 12,086 & 3,521 & 6,763 \\
\hline Wave & 9 & 2 & 2 \\
\hline Year conducted & 2008 & 2009 & 2008 \\
\hline Number of units with positive weights & 11,346 & 3,987 & 5,689 \\
\hline Wave & 10 & 3 & 3 \\
\hline Year conducted & 2010 & 2011 & 2010 \\
\hline Number of units with positive weights & 14,682 & 4,352 & 5,206 \\
\hline
\end{tabular}

HRS = Health and Retirement Study (United States), JSTAR = Japanese Study of Aging and Retirement, KLOSA $=$ Korean Longitudinal Study of Aging.

Table 3. Sample Descriptive Statistics

\begin{tabular}{|l|c|c|c|}
\hline & HRS & JSTAR & KLOSA \\
\hline \multicolumn{2}{|c|}{$2006-2007$ (Wave 1) } & \\
\hline Age & 65.8 & 65.0 & 59.1 \\
\hline Household size & 2.12 & 2.92 & 3.10 \\
\hline Male & $52.8 \%$ & $52.0 \%$ & $52.0 \%$ \\
\hline Coupled $^{\text {a }}$ & $53.1 \%$ & $82.4 \%$ & $47.2 \%$ \\
\hline Educational attainment $^{\mathrm{b}}$ & 2.57 & 1.93 & 1.71 \\
\hline Retired & $36.3 \%$ & $14.7 \%$ & $15.4 \%$ \\
\hline Work & $44.8 \%$ & $44.5 \%$ & $43.5 \%$ \\
\hline Receiving private pension & $30.3 \%$ & $16.4 \%$ & $3.2 \%$ \\
\hline Receiving public pension & $59.3 \%$ & $68.9 \%$ & $10.9 \%$ \\
\hline Self-reported good health & $71.8 \%$ & $78.8 \%$ & $50.9 \%$ \\
\hline Income (\$'000) & 76.31 & 38.07 & 23.99 \\
\hline
\end{tabular}




\begin{tabular}{|c|c|c|c|}
\hline Financial wealth (\$’000) & 140.4 & 132.0 & 2.92 \\
\hline Homeownership & $77.5 \%$ & $79.7 \%$ & $53.2 \%$ \\
\hline Primary residence $\left(\$^{\prime} 000\right)$ & 217.2 & 138.0 & 107.5 \\
\hline Net worth $\left(\$^{\prime} 000\right)$ & 531.9 & 310.0 & 165.4 \\
\hline \multicolumn{4}{|c|}{ 2008-2009 (Wave 2) } \\
\hline Age & 67.1 & 65.3 & 60.6 \\
\hline Household size & 2.10 & 2.62 & 3.09 \\
\hline Male & $53.4 \%$ & $58.6 \%$ & $60.7 \%$ \\
\hline Coupled & $52.2 \%$ & $56.8 \%$ & $47.0 \%$ \\
\hline Educational attainment & 2.58 & 2.00 & 1.68 \\
\hline Retired & $39.3 \%$ & $13.3 \%$ & $19.8 \%$ \\
\hline Work & $42.9 \%$ & $46.6 \%$ & $45.5 \%$ \\
\hline Receiving private pension & $30.8 \%$ & $18.3 \%$ & $3.8 \%$ \\
\hline Receiving public pension & $62.7 \%$ & $66.9 \%$ & $16.2 \%$ \\
\hline Self-reported good health & $71.7 \%$ & $78.4 \%$ & $51.3 \%$ \\
\hline Income $(\$ 000)$ & 74.0 & 31.99 & 22.27 \\
\hline Financial wealth $(\$ 000)$ & 134.5 & 97.36 & 7.96 \\
\hline Homeownership & $77.8 \%$ & $63.6 \%$ & $57.3 \%$ \\
\hline Primary residence $(\$ 000)$ & 208.4 & 139.7 & 127.8 \\
\hline Net worth $\left(\$^{\prime} 000\right)$ & 518.0 & 289.1 & 204.3 \\
\hline \multicolumn{4}{|c|}{ 2010-2011 (Wave 3) } \\
\hline Age & 64.5 & 67.3 & 62.1 \\
\hline Household size & 2.20 & 2.70 & 3.07 \\
\hline Male & $52.4 \%$ & $54.5 \%$ & $68.9 \%$ \\
\hline Coupled & $54.8 \%$ & $74.4 \%$ & $45.9 \%$ \\
\hline Educational attainment & 2.69 & 2.15 & 1.64 \\
\hline Retired & $33.2 \%$ & $15.5 \%$ & $20.0 \%$ \\
\hline Work & $47.1 \%$ & $49.3 \%$ & $44.7 \%$ \\
\hline Receiving private pension & $22.7 \%$ & $12.3 \%$ & $4.5 \%$ \\
\hline Receiving public pension & $55.3 \%$ & $78.4 \%$ & $22.1 \%$ \\
\hline Self-reported good health & $74.2 \%$ & $84.8 \%$ & $48.4 \%$ \\
\hline Income $(\$ 000)$ & 71.72 & 34.54 & 21.13 \\
\hline Financial wealth $\left(\$^{\prime} 000\right)$ & 122.9 & 98.81 & 11.12 \\
\hline Homeownership & $76.4 \%$ & $45.4 \%$ & $57.3 \%$ \\
\hline Primary residence $(\$ \prime 000)$ & 184.5 & 97.2 & 115.8 \\
\hline Net worth $\left(\$ \$^{\prime} 000\right)$ & 449.9 & 238.7 & 201.5 \\
\hline
\end{tabular}

HRS = Health and Retirement Study (United States), JSTAR = Japanese Study of Aging and Retirement, KLoSA $=$ Korean Longitudinal Study of Aging.

${ }^{\text {a }}$ Coupled is a dummy variable indicating whether a couple lives in the household. Survey respondents who are separated, divorced, or widowed are not considered coupled.

${ }^{\mathrm{b}}$ Educational attainment is classified as 1 for respondents with an educational attainment less than a high school degree; 2 for high school graduates; 3 for those with some college; and 4 for those with a college degree or higher. 
Table 4. Percentage Retired by Age

\begin{tabular}{|c|c|c|c|}
\hline Age brackets & HRS & JSTAR & KLoSA \\
\hline \multicolumn{4}{|c|}{ 2006-2007 } \\
\hline All ages & $36.3 \%$ & $14.8 \%$ & $15.4 \%$ \\
\hline Age $<60$ & $5.0 \%$ & $0.3 \%$ & $8.0 \%$ \\
\hline $60<=$ Age $<65$ & $26.1 \%$ & $5.5 \%$ & $18.2 \%$ \\
\hline $65<=$ Age $<70$ & $50.5 \%$ & $21.4 \%$ & $26.8 \%$ \\
\hline Age $>=70$ & $68.8 \%$ & $25.8 \%$ & $28.8 \%$ \\
\hline \multicolumn{4}{|c|}{ 2008-2009 } \\
\hline All ages & $39.3 \%$ & $13.3 \%$ & $19.8 \%$ \\
\hline Age $<60$ & $5.8 \%$ & $0.6 \%$ & $9.3 \%$ \\
\hline $60<=$ Age $<65$ & $24.3 \%$ & $8.13 \%$ & $24.5 \%$ \\
\hline $65<=$ Age $<70$ & $47.5 \%$ & $19.8 \%$ & $28.7 \%$ \\
\hline Age $>=70$ & $70.2 \%$ & $21.0 \%$ & $37.1 \%$ \\
\hline \multicolumn{4}{|c|}{$2010-2011$} \\
\hline All ages & $33.2 \%$ & $14.5 \%$ & $20.0 \%$ \\
\hline Age $<60$ & $3.6 \%$ & $0.7 \%$ & $9.2 \%$ \\
\hline $60<=$ Age $<65$ & $22.2 \%$ & $4.8 \%$ & $21.5 \%$ \\
\hline $65<=$ Age $<70$ & $49.8 \%$ & $17.1 \%$ & $29.0 \%$ \\
\hline Age $>=70$ & $70.4 \%$ & $25.4 \%$ & $35.8 \%$ \\
\hline
\end{tabular}

HRS = Health and Retirement Study (United States), JSTAR = Japanese Study of Aging and Retirement, KLoSA $=$ Korean Longitudinal Study of Aging.

Table 5. Percentage Working by Age

\begin{tabular}{|c|c|c|c|}
\hline Age brackets & HRS & JSTAR & KLoSA \\
\hline \multicolumn{4}{|c|}{ 2006-2007 } \\
\hline All ages & $44.8 \%$ & $44.5 \%$ & $43.5 \%$ \\
\hline Age $<60$ & $74.2 \%$ & $92.2 \%$ & $59.1 \%$ \\
\hline $60<=$ Age $<65$ & $54.6 \%$ & $60.7 \%$ & $36.4 \%$ \\
\hline $65<=$ Age $<70$ & $34.6 \%$ & $33.1 \%$ & $29.2 \%$ \\
\hline Age $>=70$ & $13.0 \%$ & $8.9 \%$ & $10.5 \%$ \\
\hline \multicolumn{4}{|c|}{ 2008-2009 } \\
\hline All ages & $42.9 \%$ & $46.6 \%$ & $45.5 \%$ \\
\hline Age $<60$ & $72.9 \%$ & $70.9 \%$ & $63.2 \%$ \\
\hline $60<=$ Age $<65$ & $57.4 \%$ & $64.3 \%$ & $39.8 \%$ \\
\hline $65<=$ Age $<70$ & $39.2 \%$ & $45.3 \%$ & $31.8 \%$ \\
\hline Age $>=70$ & $13.1 \%$ & $23.8 \%$ & $14.4 \%$ \\
\hline \multicolumn{4}{|c|}{ 2010-2011 } \\
\hline All ages & $47.1 \%$ & $49.3 \%$ & $44.7 \%$ \\
\hline Age $<60$ & $73.2 \%$ & $77.1 \%$ & $63.4 \%$ \\
\hline $60<=$ Age $<65$ & $53.9 \%$ & $70.7 \%$ & $42.7 \%$ \\
\hline $65<=$ Age $<70$ & $38.0 \%$ & $48.9 \%$ & $28.7 \%$ \\
\hline Age $>=70$ & $13.7 \%$ & $29.1 \%$ & $16.8 \%$ \\
\hline
\end{tabular}

HRS $=$ Health and Retirement Study (United States), JSTAR = Japanese Study of Aging and Retirement, KLoSA $=$ Korean Longitudinal Study of Aging. 
Table 6. Percentage Receiving Public Pension by Age

\begin{tabular}{|c|c|c|c|}
\hline & HRS & JSTAR & KLoSA \\
\hline \multicolumn{4}{|c|}{ 2006-2007 } \\
\hline All ages & $59.3 \%$ & $68.9 \%$ & $10.9 \%$ \\
\hline Age $<60$ & $16.0 \%$ & $8.1 \%$ & $3.2 \%$ \\
\hline $60<=$ Age $<65$ & $46.9 \%$ & $78.8 \%$ & $32.5 \%$ \\
\hline $65<=$ Age $<70$ & $92.3 \%$ & $95.8 \%$ & $30.1 \%$ \\
\hline Age $>=70$ & $98.3 \%$ & $97.8 \%$ & $10.8 \%$ \\
\hline \multicolumn{4}{|c|}{ 2008-2009 } \\
\hline All ages & $62.7 \%$ & $66.9 \%$ & $16.2 \%$ \\
\hline Age $<60$ & $18.0 \%$ & $11.1 \%$ & $5.3 \%$ \\
\hline $60<=$ Age $<65$ & $42.5 \%$ & $67.6 \%$ & $38.1 \%$ \\
\hline $65<=$ Age $<70$ & $88.9 \%$ & $94.1 \%$ & $41.0 \%$ \\
\hline Age $>=70$ & $98.1 \%$ & $93.3 \%$ & $17.4 \%$ \\
\hline \multicolumn{4}{|c|}{ 2010-2011 } \\
\hline All ages & $55.3 \%$ & $78.4 \%$ & $22.1 \%$ \\
\hline Age $<60$ & $16.1 \%$ & $16.1 \%$ & $7.5 \%$ \\
\hline $60<=$ Age $<65$ & $44.3 \%$ & $75.3 \%$ & $42.9 \%$ \\
\hline $65<=$ Age $<70$ & $90.0 \%$ & $96.8 \%$ & $50.0 \%$ \\
\hline Age $>=70$ & $97.9 \%$ & $96.0 \%$ & $27.0 \%$ \\
\hline
\end{tabular}

HRS = Health and Retirement Study (United States), JSTAR = Japanese Study of Aging and Retirement, KLoSA $=$ Korean Longitudinal Study of Aging.

Table 7. Percentage Receiving Private Pension by Age

\begin{tabular}{|c|c|c|c|}
\hline & HRS & JSTAR & KLoSA \\
\hline \multicolumn{4}{|c|}{ 2006-2007 } \\
\hline All ages & $30.3 \%$ & $16.4 \%$ & $3.2 \%$ \\
\hline Age $<60$ & $9.4 \%$ & $17.6 \%$ & $1.4 \%$ \\
\hline $60<=$ Age $<65$ & $29.1 \%$ & $20.3 \%$ & $7.4 \%$ \\
\hline $65<=$ Age $<70$ & $40.7 \%$ & $19.7 \%$ & $6.0 \%$ \\
\hline Age $>=70$ & $49.0 \%$ & $12.6 \%$ & $4.7 \%$ \\
\hline \multicolumn{4}{|c|}{ 2008-2009 } \\
\hline All ages & $30.1 \%$ & $18.3 \%$ & $3.8 \%$ \\
\hline Age $<60$ & $10.6 \%$ & $10.3 \%$ & $1.3 \%$ \\
\hline $60<=$ Age $<65$ & $24.8 \%$ & $24.2 \%$ & $8.5 \%$ \\
\hline $65<=$ Age $<70$ & $39.9 \%$ & $25.7 \%$ & $6.6 \%$ \\
\hline Age $>=70$ & $46.2 \%$ & $18.4 \%$ & $5.7 \%$ \\
\hline \multicolumn{4}{|c|}{$2010-2011$} \\
\hline All ages & $22.7 \%$ & $12.3 \%$ & $4.5 \%$ \\
\hline Age $<60$ & $4.7 \%$ & $2.0 \%$ & $1.8 \%$ \\
\hline $60<=$ Age $<65$ & $20.3 \%$ & $14.8 \%$ & $8.8 \%$ \\
\hline $65<=$ Age $<70$ & $34.5 \%$ & $17.9 \%$ & $8.3 \%$ \\
\hline Age $>=70$ & $42.5 \%$ & $12.6 \%$ & $5.5 \%$ \\
\hline
\end{tabular}

HRS = Health and Retirement Study (United States), JSTAR = Japanese Study of Aging and Retirement, KLoSA $=$ Korean Longitudinal Study of Aging. 
Table 8. Income Distribution for Whole Sample and Retired (\$'000)

\begin{tabular}{|c|c|c|c|c|c|c|c|c|c|c|}
\hline & \multicolumn{5}{|c|}{ Whole Sample } & \multicolumn{5}{|c|}{ Retired } \\
\hline & $10 \%$ & $25 \%$ & Median & $75 \%$ & $90 \%$ & $10 \%$ & $25 \%$ & Median & $75 \%$ & $90 \%$ \\
\hline \multicolumn{11}{|c|}{ 2006-2007 } \\
\hline HRS & 10.6 & 19.5 & 41.3 & 81.1 & 146.1 & 10.9 & 17.1 & 30.9 & 54.3 & 91.8 \\
\hline JSTAR & 8.74 & 18.9 & 32.9 & 52.4 & 73.4 & 8.65 & 15.7 & 27.1 & 41.9 & 61.2 \\
\hline KLoSA & 0 & 0.17 & 11.8 & 33.6 & 65.0 & 0 & 0 & 1.68 & 13.7 & 38.6 \\
\hline \multicolumn{11}{|c|}{ 2008-2009 } \\
\hline HRS & 10.1 & 18.8 & 40.5 & 79.6 & 142.4 & 10.3 & 16.4 & 30.3 & 56.0 & 98.1 \\
\hline JSTAR & 6.18 & 13.2 & 24.3 & 39.7 & 61.8 & 7.06 & 15.9 & 26.5 & 39.7 & 59.5 \\
\hline KLoSA & 0 & 1.55 & 13.9 & 32.5 & 57.4 & 0 & 0.16 & 2.94 & 14.9 & 33.9 \\
\hline \multicolumn{11}{|c|}{ 2010-2011 } \\
\hline HRS & 10.5 & 19.8 & 42.5 & 85.1 & 156.2 & 10.8 & 17.1 & 31.6 & 56.2 & 94.0 \\
\hline JSTAR & 9.02 & 17.1 & 28.9 & 45.1 & 69.0 & 9.19 & 18.1 & 27.1 & 39.3 & 58.7 \\
\hline KLoSA & 0 & 2.0 & 14.1 & 29.5 & 57.1 & 0 & 0.43 & 4.00 & 15.7 & 33.3 \\
\hline
\end{tabular}

HRS $=$ Health and Retirement Study (United States), JSTAR = Japanese Study of Aging and Retirement, KLoSA $=$ Korean Longitudinal Study of Aging.

Table 9. Median Percentage of Total Income Received from Total Pension Income for 65 and Older by Income Quartile

\begin{tabular}{|l|c|c|c|c|c|}
\hline & & \multicolumn{5}{c|}{ Income Quartiles } \\
\hline & Overall & 1st & 2nd & 3rd & 4th \\
\hline \multicolumn{7}{|c|}{$\mathbf{2 0 0 6 - 2 0 0 7}$} \\
\hline HRS & 85.7 & 100 & 95.4 & 76.3 & 36.9 \\
\hline JSTAR & 77.3 & 120 & 97.1 & 76.0 & 36.3 \\
\hline \multicolumn{7}{|c|}{$\mathbf{2 0 0 8 - 2 0 0 9}$} \\
\hline HRS & 84.1 & 100 & 93.3 & 72.2 & 31.7 \\
\hline JSTAR & 80.0 & 103 & 96.4 & 80.0 & 40.0 \\
\hline \multicolumn{7}{|c|}{$\mathbf{2 0 1 0 - 2 0 1 1}$} \\
\hline HRS & 85.1 & 100 & 95.6 & 76.2 & 32.4 \\
\hline JSTAR & 76.7 & 103 & 94.3 & 70.0 & 41.0 \\
\hline
\end{tabular}

HRS $=$ Health and Retirement Study (United States), JSTAR = Japanese Study of Aging and Retirement.

Note: We chose not to report the results for the Korean Longitudinal Study of Aging (KLoSA) because median percentages are mostly zero, the highest being 10\% for the 4th quartile in 2010. 
Table 10. Wealth Distribution for Whole Sample and Retired (\$'000)

\begin{tabular}{|c|c|c|c|c|c|c|c|c|c|c|}
\hline & \multicolumn{5}{|c|}{ Whole Sample } & \multicolumn{5}{|c|}{ Retired } \\
\hline & $10 \%$ & $25 \%$ & Median & $75 \%$ & $90 \%$ & $10 \%$ & $25 \%$ & Median & $75 \%$ & $90 \%$ \\
\hline \multicolumn{11}{|c|}{$2006-2007$} \\
\hline HRS & 0.65 & 44.0 & 202.3 & 557.2 & 1,219 & 4.11 & 71.8 & 269.4 & 643.7 & 1,308 \\
\hline JSTAR & 0 & 61.2 & 227.1 & 436.8 & 742.5 & 0 & 52.4 & 209.7 & 436.8 & 698.9 \\
\hline KLoSA & 0 & 5.6 & 70.0 & 191.5 & 401.6 & 0 & 2.8 & 65.8 & 202.2 & 432.8 \\
\hline \multicolumn{11}{|c|}{ 2008-2009 } \\
\hline HRS & 0.61 & 40.7 & 189.2 & 532.9 & 1,174 & 3.04 & 64.8 & 249.5 & 625.7 & 1,290 \\
\hline JSTAR & 0.0 & 26.5 & 164.2 & 361.4 & 713.6 & 8.65 & 84.4 & 216.3 & 379.5 & 697.3 \\
\hline KLoSA & 0 & 12.9 & 91.9 & 253.0 & 515.7 & 1 & 2.58 & 77.4 & 257.9 & 555.2 \\
\hline \multicolumn{11}{|c|}{ 2010-2011 } \\
\hline HRS & 0 & 25.7 & 154.0 & 464.0 & 1,063 & 4.13 & 69.5 & 241.8 & 593.8 & 1,204 \\
\hline JSTAR & 0 & 9.93 & 135.3 & 328.7 & 615.5 & 0 & 45.1 & 180.5 & 357.3 & 604.5 \\
\hline KLoSA & 0 & 11.9 & 95.5 & 249.7 & 500.0 & 0 & 3.57 & 71.4 & 237.8 & 444.9 \\
\hline
\end{tabular}

HRS = Health and Retirement Study (United States), JSTAR = Japanese Study of Aging and Retirement, KLoSA $=$ Korean Longitudinal Study of Aging.

Table 11. Financial Wealth Distribution (\$'000)

\begin{tabular}{|l|c|c|c|c|c|c|c|c|c|c|}
\hline & \multicolumn{9}{c|}{ Whole Sample } & \multicolumn{7}{c|}{ Retired } \\
\hline & $10 \%$ & $25 \%$ & Median & $75 \%$ & $90 \%$ & $10 \%$ & $25 \%$ & Median & $75 \%$ & $90 \%$ \\
\hline \multicolumn{8}{|c|}{$2006-2007$} \\
\hline HRS & -3.72 & 0.54 & 10.8 & 92.0 & 326.7 & 0.0 & 1.3 & 27.0 & 153.6 & 447.9 \\
\hline JSTAR & 0 & 13.8 & 52.4 & 131.0 & 262.1 & 0 & 8.74 & 52.4 & 124.5 & 262.1 \\
\hline KLoSA & -25.2 & 0 & 0 & 7.0 & 30.8 & -9.6 & 0 & 0 & 5.6 & 33.5 \\
\hline \multicolumn{10}{|c|}{$2008-2009$} \\
\hline HRS & -4.56 & 0.0 & 10.13 & 100.3 & 330.3 & 0.0 & 1.01 & 27.4 & 152.0 & 461.0 \\
\hline JSTAR & 0 & 2.65 & 30.9 & 123.6 & 220.7 & 0 & 8.83 & 44.6 & 176.5 & 285.1 \\
\hline KLOSA & -6.45 & 0 & 0 & 7.74 & 38.7 & 0 & 0 & 0 & 6.45 & 38.7 \\
\hline \multicolumn{8}{|c|}{$2010-2011$} & & & \\
\hline HRS & -8.0 & 0 & 7.0 & 75.5 & 300.0 & -0.15 & 0.99 & 25.0 & 142.0 & 432.1 \\
\hline JSTAR & 0 & 9.02 & 54.1 & 143.8 & 261.7 & 0 & 18.0 & 74.0 & 162.0 & 316.0 \\
\hline KLOSA & 0 & 0 & 0 & 9.51 & 39.2 & 0 & 0 & 0 & 5.95 & 35.7 \\
\hline
\end{tabular}

HRS = Health and Retirement Study (United States), JSTAR = Japanese Study of Aging and Retirement, KLOSA $=$ Korean Longitudinal Study of Aging. 
Table 12. Stock Ownership

\begin{tabular}{|l|c|c|c|c|c|c|}
\hline & \multicolumn{2}{c|}{ HRS } & \multicolumn{2}{c|}{ JSTAR } & \multicolumn{2}{c|}{ KLoSA } \\
\hline & $\begin{array}{c}\text { Whole } \\
\text { sample }\end{array}$ & Retired & $\begin{array}{c}\text { Whole } \\
\text { sample }\end{array}$ & Retired & $\begin{array}{c}\text { Whole } \\
\text { sample }\end{array}$ & Retired \\
\hline \multicolumn{7}{|c|}{$\mathbf{2 0 0 6 - 2 0 0 7}$} \\
\hline Overall & $27.9 \%$ & $32.6 \%$ & $13.1 \%$ & $11.6 \%$ & $2.4 \%$ & $2.1 \%$ \\
\hline Given positive wealth & $30.2 \%$ & $34.3 \%$ & $14.4 \%$ & $13.4 \%$ & $2.8 \%$ & $2.7 \%$ \\
\hline Given positive financial & $36.1 \%$ & $38.7 \%$ & $15.1 \%$ & $12.7 \%$ & $4.5 \%$ & $4.2 \%$ \\
\hline Median value (\$'000) & 70.3 & 108.2 & 26.2 & 34.9 & 14.0 & 19.5 \\
\hline \multicolumn{7}{|c|}{$\mathbf{2 0 0 8 - 2 0 0 9}$} \\
\hline Overall & $26.5 \%$ & $30.6 \%$ & $12.2 \%$ & $13.6 \%$ & $3.4 \%$ & $2.6 \%$ \\
\hline Given positive wealth & $28.7 \%$ & $32.2 \%$ & $13.7 \%$ & $14.5 \%$ & $4.0 \%$ & $3.3 \%$ \\
\hline Given positive financial & $34.7 \%$ & $36.6 \%$ & $15.0 \%$ & $15.3 \%$ & $6.7 \%$ & $5.9 \%$ \\
\hline Median value (\$'000) & 81.1 & 101.3 & 17.7 & 17.7 & 23.9 & 25.8 \\
\hline \multicolumn{7}{|c|}{$\mathbf{2 0 1 0 - 2 0 1 1}$} \\
\hline Overall & $25.6 \%$ & $30.2 \%$ & $21.0 \%$ & $26.1 \%$ & $2.1 \%$ & $1.0 \%$ \\
\hline Given positive wealth & $28.5 \%$ & $32.0 \%$ & $24.2 \%$ & $26.8 \%$ & $2.4 \%$ & $1.3 \%$ \\
\hline Given positive financial & $35.5 \%$ & $37.0 \%$ & $23.6 \%$ & $28.9 \%$ & $4.1 \%$ & $2.0 \%$ \\
\hline Median value (\$'000) & 62.0 & 100.0 & 18.1 & 18.1 & 35.7 & 47.6 \\
\hline
\end{tabular}

HRS = Health and Retirement Study (United States), JSTAR = Japanese Study of Aging and Retirement, KLoSA = Korean Longitudinal Study of Aging.

Table 13. Participation Decision for Stocks, 2006-2007 Wave

\begin{tabular}{|c|c|c|c|}
\hline Characteristics & HRS & JSTAR & KLOSA \\
\hline Intercept & -6.438 & -2.281 & 0.265 \\
& $(-9.42)$ & $(-2.70)$ & -0.00112 \\
\hline Age & -0.0348 & 0.0579 & $(-3.45)$ \\
\hline Age & $(-1.83)$ & $(2.16)$ & 0.0000787 \\
& 0.00032 & -0.00045 & $(3.19)$ \\
\hline Education & $(2.40)$ & $(-2.17)$ & 0.0216 \\
& 0.205 & 0.067 & $(7.95)$ \\
\hline Health & $(12.4)$ & $(7.79)$ & -0.00293 \\
& 0.128 & 0.0097 & $(-0.63)$ \\
\hline log(income) & $(3.38)$ & $(0.49)$ & 0.0005 \\
& 0.105 & 0.0154 & $(0.82)$ \\
\hline log(net worth) & $(5.94)$ & $(3.28)$ & 0.0102 \\
& 0.401 & 0.0238 & $(6.63)$ \\
\hline Gender & $(29.9)$ & $(3.66)$ & -0.0064 \\
& -0.0639 & -0.0138 & $(-1.34)$ \\
\hline Coupled & $(-1.98)$ & $(-0.73)$ & -0.0017 \\
& -0.0974 & -0.00102 & $(-0.34)$ \\
\hline Retired & $(-2.77)$ & $(-0.04)$ & 0.0036 \\
& 0.103 & 0.0138 & $(0.63)$ \\
\hline PrivatePension & $(2.70)$ & $(0.57)$ & -0.0146 \\
& 0.0823 & 0.0772 & $(-1.45)$ \\
\hline & $(2.38)$ & $(3.91)$ & \\
\hline
\end{tabular}


HRS = United States Health and Retirement Study, JSTAR = Japanese Study of Aging and Retirement, KLoSA $=$ Korean Longitudinal Study of Aging.

Note: The table shows the results of a probit analysis on stock ownership for households with positive net worth and household heads older than 50. T-statistics are in parentheses.

Source: Authors' estimates.

Table 14. Participation Decision for Stocks, 2008-2009 Wave

\begin{tabular}{|c|c|c|c|}
\hline Characteristics & HRS & JSTAR & KLoSA \\
\hline Intercept & -6.123 & -1.329 & 0.529 \\
& $(-8.25)$ & $(-2.17)$ & $(4.25)$ \\
\hline Age & -0.0444 & 0.0235 & -0.0194 \\
& $(-2.16)$ & $(1.21)$ & $(-5.13)$ \\
\hline Age ${ }^{2}$ & 0.000374 & -0.000182 & 0.000135 \\
& $(2.62)$ & $(-1.21)$ & $(4.74)$ \\
\hline Education & 0.192 & 0.0727 & 0.0181 \\
& $(11.2)$ & $(9.48)$ & $(5.59)$ \\
\hline Health & 0.0733 & 0.00737 & 0.0049 \\
& $(1.79)$ & $(0.44)$ & $0.87)$ \\
\hline log(income) & 0.103 & 0.0372 & $(2.27)$ \\
& $(5.97)$ & $(1.05)$ & 0.0118 \\
& 0.414 & 0.0426 & $(6.70)$ \\
\hline log(net worth) & $(29.4)$ & $(9.51)$ & -0.00827 \\
& -0.0946 & 0.00244 & $(-1.49)$ \\
\hline Gender & $(-2.83)$ & $(0.15)$ & -0.0188 \\
& -0.0775 & 0.00654 & $(-3.31)$ \\
\hline Coupled & $(-2.13)$ & $(0.42)$ & 0.0118 \\
& 0.0959 & -0.00638 & $(6.70)$ \\
\hline Retired & $(2.47)$ & $(-0.29)$ & 0.00836 \\
& 0.0576 & 0.0972 & $(0.48)$ \\
\hline PrivatePension & $(2.62)$ & $(5.20)$ & \\
& & &
\end{tabular}

HRS = United States Health and Retirement Study, JSTAR = Japanese Study of Aging and Retirement, KLoSA = Korean Longitudinal Study of Aging.

Note: The table shows the results of a probit analysis on stock ownership for households with positive net worth and household heads older than 50. T-statistics are in parentheses.

Source: Authors' estimates. 
Table 15. Participation Decision for Stocks, 2010-2011 Wave

\begin{tabular}{|c|c|c|c|}
\hline Characteristics & HRS & JSTAR & KLoSA \\
\hline Intercept & $\begin{array}{l}-4.899 \\
(-8.05)\end{array}$ & $\begin{array}{l}-0.571 \\
(-0.58)\end{array}$ & $\begin{array}{r}-0.0637 \\
(-0.65)\end{array}$ \\
\hline Age & $\begin{array}{c}-0.0716 \\
(-4.19)\end{array}$ & $\begin{array}{c}-0.0058 \\
(-0.19)\end{array}$ & $\begin{array}{c}-0.00056 \\
(-0.19)\end{array}$ \\
\hline $\mathrm{Age}^{2}$ & $\begin{array}{c}0.000552 \\
(2.62)\end{array}$ & $\begin{array}{c}0.00004 \\
(0.17)\end{array}$ & $\begin{array}{c}0.00000057 \\
(0.03)\end{array}$ \\
\hline Education & $\begin{array}{l}0.163 \\
(9.92)\end{array}$ & $\begin{array}{l}0.0509 \\
(3.82)\end{array}$ & $\begin{array}{c}0.0144 \\
(5.39)\end{array}$ \\
\hline Health & $\begin{array}{l}0.161 \\
(4.10) \\
\end{array}$ & $\begin{array}{c}0.00054 \\
(0.02) \\
\end{array}$ & $\begin{array}{c}0.000825 \\
(0.18)\end{array}$ \\
\hline log(income) & $\begin{array}{c}0.0932 \\
(6.00)\end{array}$ & $\begin{array}{c}0.00103 \\
(1.20)\end{array}$ & $\begin{array}{c}0.000725 \\
(1.02)\end{array}$ \\
\hline $\log$ (net worth) & $\begin{array}{l}0.402 \\
(31.0)\end{array}$ & $\begin{array}{c}0.0627 \\
(7.76)\end{array}$ & $\begin{array}{c}0.0085 \\
(5.82)\end{array}$ \\
\hline Gender & $\begin{array}{c}0.00462 \\
(0.15)\end{array}$ & $\begin{array}{r}-0.0457 \\
(-1.69)\end{array}$ & $\begin{array}{c}-0.0191 \\
(-3.94)\end{array}$ \\
\hline Coupled & $\begin{array}{c}-0.0588 \\
(-1.73)\end{array}$ & $\begin{array}{c}0.0101 \\
(2.89) \\
\end{array}$ & $\begin{array}{c}-0.00976 \\
(-2.07)\end{array}$ \\
\hline Retired & $\begin{array}{l}0.0327 \\
(0.086)\end{array}$ & $\begin{array}{l}0.030 \\
(0.81)\end{array}$ & $\begin{array}{c}-0.00666 \\
(-1.23)\end{array}$ \\
\hline PrivatePension & $\begin{array}{l}0.141 \\
(3.93)\end{array}$ & $\begin{array}{l}0.114 \\
(1.63)\end{array}$ & $\begin{array}{l}0.0126 \\
(1.32)\end{array}$ \\
\hline
\end{tabular}

HRS = United States Health and Retirement Study, JSTAR = Japanese Study of Aging and Retirement, KLoSA = Korean Longitudinal Study of Aging.

Note: The table shows the results of a probit analysis on stock ownership for households with positive net worth and household heads older than 50. T-statistics are in parentheses.

Source: Authors' estimates.

Table 16. Decomposition of Differences in Participation Decision for Stocks Using United States as the Base

\begin{tabular}{|c|c|c|c|c|c|c|}
\hline Wave & \multicolumn{3}{|c|}{ Japan } & \multicolumn{3}{c|}{ Republic of Korea } \\
\hline difference & $\begin{array}{c}\text { Difference } \\
\text { due to } \\
\text { covariates }\end{array}$ & $\begin{array}{c}\text { Difference } \\
\text { due to } \\
\text { coefficients }\end{array}$ & $\begin{array}{c}\text { Total } \\
\text { difference }\end{array}$ & $\begin{array}{c}\text { Difference } \\
\text { due to } \\
\text { covariates }\end{array}$ & $\begin{array}{c}\text { Difference } \\
\text { due to } \\
\text { coefficients }\end{array}$ \\
\hline 1) 2006-2007 & $15.96 \%$ & $7.72 \%$ & $8.24 \%$ & $28.21 \%$ & $20.78 \%$ & $7.43 \%$ \\
& $(11.2)$ & $(11.9)$ & & $(42.2)$ & $(16.9)$ \\
\hline 2) 2008-2009 & $15.06 \%$ & $9.82 \%$ & $5.24 \%$ & $26.05 \%$ & $17.15 \%$ & $8.90 \%$ \\
& & $(17.5)$ & $(9.36)$ & & $(32.4)$ & $(16.8)$ \\
\hline 3) 2010-2011 & $4.51 \%$ & $9.16 \%$ & $-4.65 \%$ & $26.85 \%$ & $15.85 \%$ & $11.00 \%$ \\
& & $(15.8)$ & $(-8.02)$ & & $(29.9)$ & $(20.8)$ \\
\hline
\end{tabular}

Note: See Section V.D. for a description of the decomposition analysis. T-statistics are in parentheses.

Source: Authors' estimates. 